\title{
Hydrological Evaluation of Satellite Soil Moisture Data in Two Basins of Different Climate and Vegetation Density Conditions
}

\author{
Lu Zhuo and Dawei Han \\ WEMRC, Department of Civil Engineering, University of Bristol, Bristol, UK \\ Correspondence should be addressed to Lu Zhuo; lu.zhuo@bristol.ac.uk
}

Received 27 July 2016; Revised 15 November 2016; Accepted 6 December 2016; Published 29 January 2017

Academic Editor: Minha Choi

Copyright ( 2017 Lu Zhuo and Dawei Han. This is an open access article distributed under the Creative Commons Attribution License, which permits unrestricted use, distribution, and reproduction in any medium, provided the original work is properly cited.

\begin{abstract}
Accurate soil moisture information is very important for real-time flood forecasting. Although satellite soil moisture observations are useful information, their validations are generally hindered by the large spatial difference with the point-based measurements, and hence they cannot be directly applied in hydrological modelling. This study adopts a widely applied operational hydrological model Xinanjiang (XAJ) as a hydrological validation tool. Two widely used microwave sensors (SMOS and AMSR-E) are evaluated, over two basins (French Broad and Pontiac) with different climate types and vegetation covers. The results demonstrate SMOS outperforms AMSR-E in the Pontiac basin (cropland), while both products perform poorly in the French Broad basin (forest). The MODIS NDVI thresholds of 0.81 and 0.64 (for cropland and forest basins, resp.) are very effective in dividing soil moisture datasets into "denser" and "thinner" vegetation periods. As a result, in the cropland, the statistical performance is further improved for both satellites (i.e., improved to NSE $=0.74$, RMSE $=0.0059 \mathrm{~m}$ and NSE $=0.58$, RMSE $=0.0066 \mathrm{~m}$ for SMOS and AMER-E, resp.). The overall assessment suggests that SMOS is of reasonable quality in estimating basin-scale soil moisture at moderate-vegetated areas, and NDVI is a useful indicator for further improving the performance.
\end{abstract}

\section{Introduction}

Soil moisture is one of the most important state variables in a hydrological model [1]. During real-time flood forecasting, satellite soil moisture can be used to match the model with the current observations prior to its use in forecasting mode-termed as updating or data assimilation [2]. This procedure is particularly essential during unusual hydrological events and after a long period of dryness [3-10]. However conventional in situ measurements are currently limited to discrete measurements at particular locations. Furthermore they are too sparse to represent the spatial soil moisture distribution and are therefore not suitable for basin level studies [7, 11-14]. Alternatively, satellite remote sensing techniques are a major tool in observing soil moisture information at a large scale [15], which provide near real-time global coverage. Several frequency bands have been used in soil moisture remote sensing including visible light, infrared, and microwave $[8,16-21]$. In this study, the focus is on the state-of-the-art microwave-band sensors. The Soil Moisture and Ocean Salinity (SMOS, [20]) is adopted in this study. The reason for choosing SMOS over the Soil Moisture Active/ Passive mission (SMAP, [19]) is due to the longer period of data records. In addition, for comparison purpose, the Advanced Microwave Scanning Radiometer on Earth Observing System (AMSR-E, [22]) is also used in the evaluation of SMOS. The AMSR-E radiometer was one of the first sensors to measure surface soil moisture as a routine product $[22,23]$.

In this study, a widely used operational hydrological model Xinanjiang (XAJ) is used directly for the satellites soil moisture evaluation, which is more scale-matched than the in situ point-based observations. Two basins (French Broad and Pontiac, resp.) with different climate types and vegetation covers are adopted. Furthermore MODIS Normalized Difference Vegetation Index (NDVI) is used to further improve the performance which has not been used in the previous literature $[4-7,10,24-28]$. The novelty of this study is hence to provide a comprehensive hydrological comparison study between SMOS and AMSR-E retrieved soil 


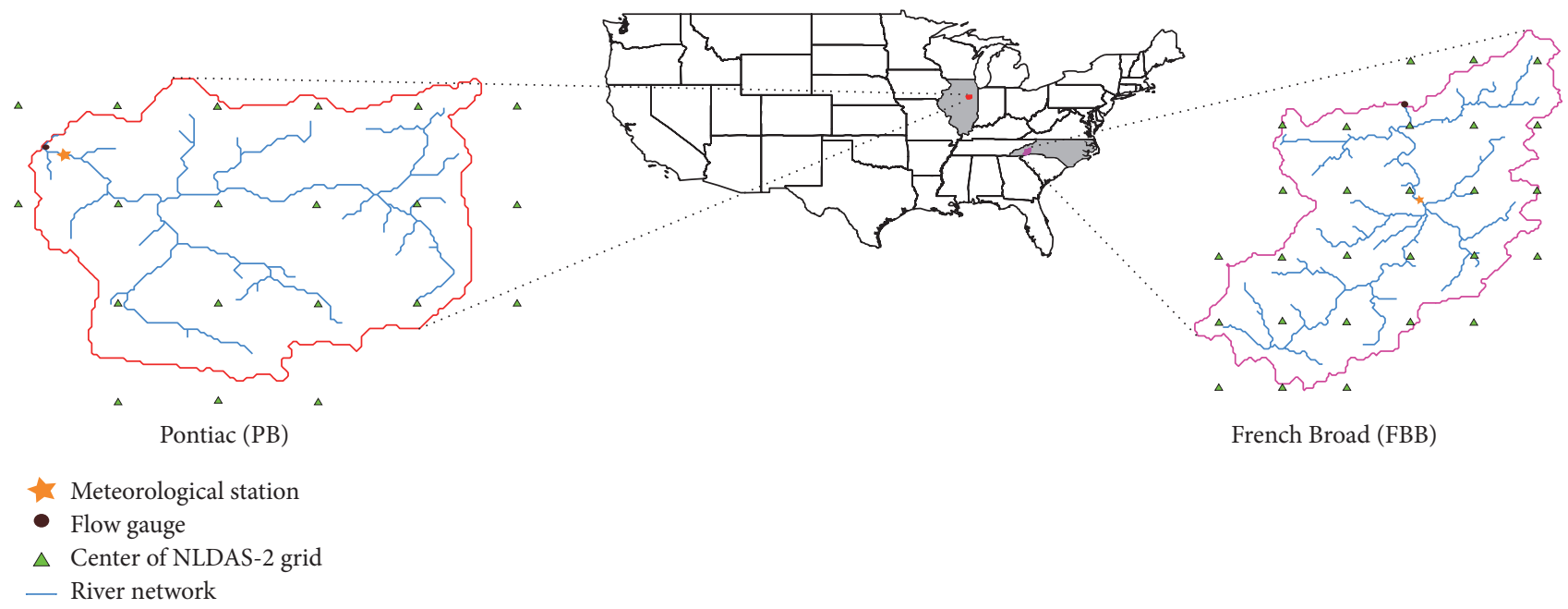

Figure 1: Locations of the Pontiac basin (PB; $1500 \mathrm{~km}^{2}$ ) and the French Broad basin (FBB; $2448 \mathrm{~km}^{2}$ ) with flow gauges and NLDAS-2 grids over river network maps.

moisture observations, with the aid of NDVI information for further enhancements. All soil moisture datasets evaluated in this study are procured for the period of January 2010 to October 2011, a period during which both SMOS and AMSRE products are available for the study areas.

\section{Study Areas and Datasets}

Two study areas are selected in the middle and east of US, respectively. The French Broad basin $\left(\mathrm{FBB} ; 2448 \mathrm{~km}^{2}\right.$ ) is a densely vegetated study area, which is located in the western North Carolina of the US $\left(35.609^{\circ} \mathrm{N}, 82.579^{\circ} \mathrm{W}\right)$, influenced primarily by the maritime temperate climate [29]. The major land use of this basin is mixed forest $[30,31]$ on Ultisols soil [32]. The average altitude of the basin is $819 \mathrm{~m}$ above mean sea level (MSL) and the average annual rainfall is $1383 \mathrm{~mm}$. The basin generally does not have significant human impacts [33]. Meanwhile, the Vermilion River at Pontiac $\left(\mathrm{PB} ; 1500 \mathrm{~km}^{2}\right.$ ) is selected as the moderately vegetated study area, which is located in mid-Illinois of the US $\left(40.878^{\circ} \mathrm{N}, 88.636^{\circ} \mathrm{W}\right)$. Its major climate type is hot summer continental climate [29]; and its land cover is predominantly cropland [30, 31] on Mollisols soil [32]. The average altitude of the basin is $188 \mathrm{~m}$ MSL and average annual rainfall is $867 \mathrm{~mm}$. The layouts of both basins are shown in Figure 1 along with the locations of their flow gauges, meteorological stations, NLDAS-2 grids, and distribution of river networks.

The NLDAS-2 [34] precipitation and potential evapotranspiration (PET) at $0.125^{\circ}$ spatial resolution and daily temporal resolution (converted from hourly resolution) are used to run the XAJ model. As shown in Figure 1, there is a total of 27 NLDAS-2 grids covering the entire FBB and 20 NLDAS-2 grids for the $\mathrm{PB}$. Both PET and precipitation datasets have been calculated into one basin-scale dataset by using the weighted average method for the usage in the lumped XAJ model. For FBB, the USGS daily flow data from January 2010 to December 2012 are used for XAJ model's calibration and validation. The datasets from the first 24 months (January 1 , 2010, to December 31, 2011) have been used for the calibration and the remaining 12 months (January 1, 2012, to December 31,2012 ) are used for the validation purpose. Meanwhile for $\mathrm{PB}$, due to missing data, the USGS daily flow data from January 2010 to April 2011 are used for calibration and the period of May 2011 to December 2011 is used for validation.

All soil moisture datasets evaluated in this study are procured for the period of January 2010 to October 2011, a period during which both SMOS and AMSR-E products are available for the study areas. Daily SMOS Level 3 data is obtained from the SMOS Barcelona Expert Center (SMOSBEC), and the daily AMSR-E Level-3 surface soil moisture product is obtained from the National Snow and Ice Data Center (NSIDC). The daily air temperature at the nearest meteorological stations (i.e., Asheville station and Pontiac station for $\mathrm{FBB}$ and $\mathrm{PB}$, resp.) for both basins is provided by the NOAA National Climatic Data Center [35]. In addition the MODIS 16-day Level-3 NDVI (MOD13C1) dataset is acquired from the NASA/USGS Land Processes Distributed Active Archive Center (LP DAAC) with a spatial resolution of $0.05^{\circ}$.

Like most operational hydrological models, XAJ treats a basin as a single unit (i.e., lumped); therefore, for all the satellite datasets, only the pixels that are within the basin area are collected and converted into one basin-scale dataset by using the weighted average method.

\section{Methodology}

3.1. The SMOS Product. The SMOS retrieves data of emitted microwave radiation at the frequency of $1.4 \mathrm{GHz}$ (L-band) with a spatial resolution of $35-50 \mathrm{~km}[20,27,36]$. SMOS offers a global coverage at the equator crossing the times of $6 \mathrm{am}$ (local solar time (LST), ascending) and $6 \mathrm{pm}$ (LST, descending) [37]. In this study the daily SMOS Level3 soil moisture product (SMOS) is used. Its stability and 
robustness have been improved by utilizing data filtering, spatial averaging, and multiorbit vegetation parameters in the retrieval method [38, 39]. The data is available from the SMOS-BEC website (http://cp34-bec.cmima.csic.es). It is found that, in much of the world, ascending SMOS soil moisture retrieval was better than that from the descending retrieval [40], which is expected because at dawn soil is often in near hydraulic equilibrium [41]. For this reason, only the daily SMOS ascending overpass is used in this study.

3.2. The AMSR-E Product. The AMSR-E was launched in June 2002 on the Aqua satellite, which was operated by the National Aeronautics and Space Administration (NASA). AMSR-E carried out passive microwave measurements with a single $55^{\circ}$ incidence angle at six different frequencies: 6.9, $10.7,18.7,23.8,36.5$, and $89.0 \mathrm{GHz}$, all dual-polarized, with a spatial resolution around $50 \mathrm{~km}$. The global swath coverage is achieved every two days or less, separately for ascending and descending passes, except for a small region near the poles. The crossing times are 1:30 am (LST, descending) and 1:30 pm (LST, ascending) [22]. The available datasets are from June 2002 to October 2011. On this latter date, AMSR-E on board the NASA Aqua satellite stopped producing data due to a problem with its antenna rotation [40].

Various algorithms have been developed to derive AMSRE soil moisture. The two most adopted ones are the NASA (NSIDC) and the VUA-NASA retrieval algorithms. In response to Radio Frequency Interference (RFI), NSIDC uses only the X-band $(10.7 \mathrm{GHz})$ frequency AMSR-E data, while the VUA-NASA algorithm is separately applied to both C(6.925 GHz) and X-band AMSR-E observations [42]. A lot of studies have already been carried out to compare the accuracy between VUA-NASA and NSIDC [8, 42-44]; therefore the comparison work is not repeated here. In this paper the AMSR-E-NASA (NSIDC) [23] product is used.

3.3. XAJ Hydrological Model. In hydrology, Soil Moisture Deficit (SMD) or depletion is an important soil moisture indicator, which demonstrates the amount of water to be added to a soil profile to bring it to the field capacity $[45,46]$. The SMD equation is shown as

$$
\mathrm{SMD}=\mathrm{FC}-\mathrm{SMC}
$$

where FC is the field capacity, which is considered as the upper limit in hydrological modelling for soil water storage; SMC is the soil moisture content. It can be seen the SMD is opposite to the SMC, so the larger the SMC, the smaller the SMD.

It has been shown that the three-layer XAJ model is very useful in modelling SMD from the hydrological data [4751]. There are some alternative XAJ formats [52-54], but this paper uses its original form because it is the most commonly used format. The XAJ model is a relatively simple operational lumped rainfall-runoff model; its main concept is the runoff generation on repletion of storage, which means that runoff is not generated until the soil water content of its aeration zone reaches the field capacity. The flowchart of the XAJ model is shown in Figure 2. The structure of XAJ model includes an evapotranspiration unit, runoff production unit, and a runoff routing unit. The model includes three soil layers (upper, lower, and deep) which represent the three evapotranspiration components. The runoff component is also known as a water balance model which simulates lumped values of runoff with given rainfall (P) and PET datasets. The simulated effective rainfall (runoff) is then routed as river flow through a routing module to the basin outlet, in which the Muskingum routing method is applied in this study. The 16 XAJ parameters are calibrated in this study by finding the optimal performance of the model $[50,55]$. The three-layer SMDs are generated to determine the effect of drying and wetting on the basin soil storage. In this study only the upper layer's SMD is used to compare with the two satellites soil moisture retrievals, because it is more scale-matched.

3.4. Performance Indicators. In this study the SMOS and AMSR-E are evaluated against the XAJ derived top layer SMD (referred to as SMD1). The five performance indicators: NashSutcliffe Efficiency (NSE) [56], Pearson product moment correlation coefficient $(r)$, correlation significance $t$-test $(t)$, Spearman rank correlation coefficient $\left(r_{\mathrm{sp}}\right)$, and Root Mean Square Error (RMSE), are used in this study. NSE is the most common and important performance measure used in hydrology and it is calculated using the following equation:

$$
\mathrm{NSE}=1-\frac{\sum_{i=1}^{n}\left(y_{i}-x_{i}\right)^{2}}{\sum_{i=1}^{n}\left(x_{i}-\bar{x}\right)^{2}}
$$

where $x_{i}$ is the observed values and $y_{i}$ is the simulated values. $n$ is the number of data pairs.

Pearson product moment correlation coefficient $(r)$ is used to evaluate the linear relationship between two variables, which is defined as

$$
r=\frac{n\left(\sum x_{i} y_{i}\right)-\left(\sum x_{i}\right)\left(\sum y_{i}\right)}{\sqrt{\left[n \sum x_{i}^{2}-\left(\sum x_{i}\right)^{2}\right]\left[n \sum y_{i}^{2}-\left(\sum y_{i}\right)^{2}\right]}} .
$$

The two-tail $t$-test is a statistical hypothesis test used to examine the statistical significance of $r$ to ascertain that there is evidence of an association between the two variables. If the calculated $t$ value is within the critical range (the critical range can be found in a $t$-test look-up table, based on different confidence levels (CI)), we accept the null hypothesis (H0) that there is no correlation between $x$ and $y$ variables [57]. On the other hand, if the $t$ value falls outside the critical range, then there is a relationship between $x$ and $y$ variables (denoted as H1). The equation is given as

$$
t=\frac{r}{\sqrt{\left(1-r^{2}\right) /(n-2)}} .
$$

Spearman rank correlation coefficient $\left(r_{\text {sp }}\right)$ is a nonparametric technique for evaluating the degree of correlation between two independent variables [58]. Due to its ability to cope with nonlinear correlation as well as linear correlation, 


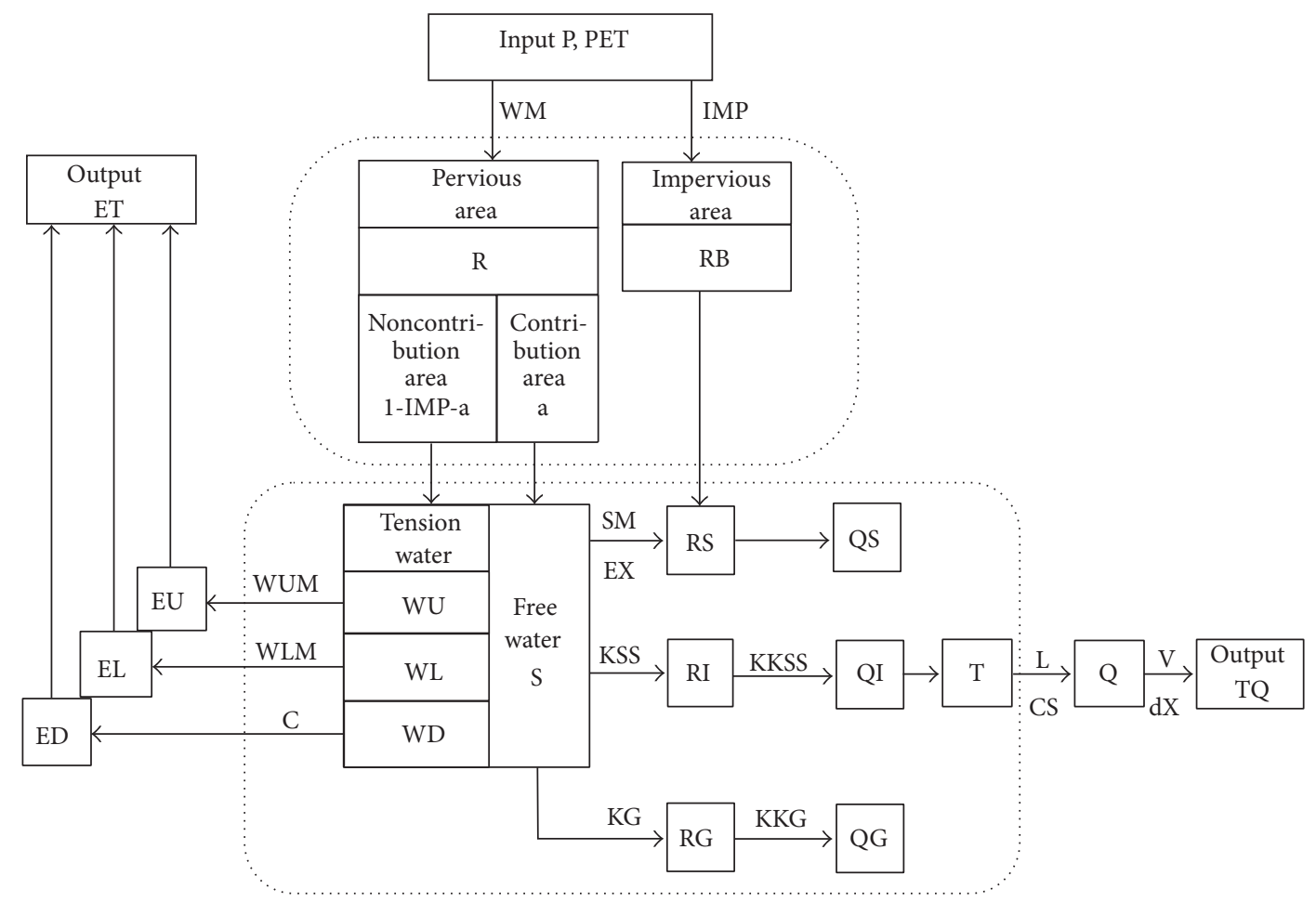

Figure 2: Adopted flowchart of the XAJ model [50], where WU, WL, and WD represent the upper, lower, and deep soil layers' areal mean tension water storage, respectively; EU, EL, and ED stand for the upper, lower, and deep soil layers' evapotranspiration output, respectively; S is the areal mean free water storage; $\mathrm{a}$ is the portion of the subcatchment which is currently producing runoff; IMP is the factor of impervious area in a catchment; $\mathrm{RB}$ is the direct runoff produced from the small portion of impervious area; $\mathrm{R}$ is the total runoff generated from the model with surface runoff (RS), interflow (RI), and groundwater runoff (RG) components, respectively. These three runoff components are then transferred into QS, QI, and QG and combined as the total subcatchment inflow (T) to the channel network. The flow outputs from each subcatchment $\mathrm{Q}$ are then routed to the catchment outlet to produce the final flow result (TQ).

it is used in addition to $r$ for a more comprehensive comparison.

$$
r_{\mathrm{sp}}=1-\frac{6 \sum_{i=1}^{n} d_{i}^{2}}{n^{3}-n}
$$

where $d_{i}$ is the difference between ranks for each soil moisture data pair $\left(x_{i}, y_{i}\right)$.

Root Mean Square Error (RMSE) is described by the following equation:

$$
\mathrm{RMSE}=\sqrt{\frac{1}{n} \sum_{i=1}^{n}\left(y_{i}-x_{i}\right)^{2}} .
$$

\section{Results and Discussion}

4.1. XAJ Simulations for SMD1 Estimation. The performance of the XAJ model is determined by the NSE coefficient as its objective function. There are 16 parameters in total used for $\mathrm{XAJ}$ initialization, and the optimal values with their initialization values used in this study are shown in Table 1 . As a result, the overall performance is represented by the NSE value of 0.81 and 0.86 for the calibration and 0.80 and 0.83 during the validation for $\mathrm{PB}$ and $\mathrm{FBB}$, respectively. In this study SMD1 generated from $\mathrm{XAJ}$ is selected as a benchmark given the fact that the $\mathrm{XAJ}$ is capable of simulating the hydrological processes in the basin, even though the model is calibrated using flow. The time series plots of rainfall and flow during the calibration and validation periods are shown in Figure 3. The modelling outcomes reveal that the XAJ model tends to match the measured flow rather well while there is a slight overestimation of low flows for $\mathrm{PB}$ and a relatively small underestimation of flow for FBB during the calibration. On the other hand, for the validation period, there is an overestimation of the overall flow simulation for $\mathrm{PB}$, while, for FBB at some parts of the validation, the flow simulation deviates slightly from the observed flow, especially at the low-flow parts of the hydrograph. Nevertheless, during most of the flow events, the XAJ model has a good performance and all NSE values are sufficiently high for an acceptable hydrological model. More details on XAJ flow modelling in $\mathrm{PB}$ basin and FBB basin are discussed in Zhuo et al. [26] and Zhuo et al. [59], respectively.

\subsection{Comparison of SMD1, SMOS, and AMSR-E Soil Moisture} over Two Selected Sites. The time series of ET, SMD1, and two satellite soil moisture products (SMOS and AMSR-E) are compared in Figure 4 for the two selected basins.

The PB is the site mainly covered by cropland subjected to frequent frozen soil events during winter periods. The time 


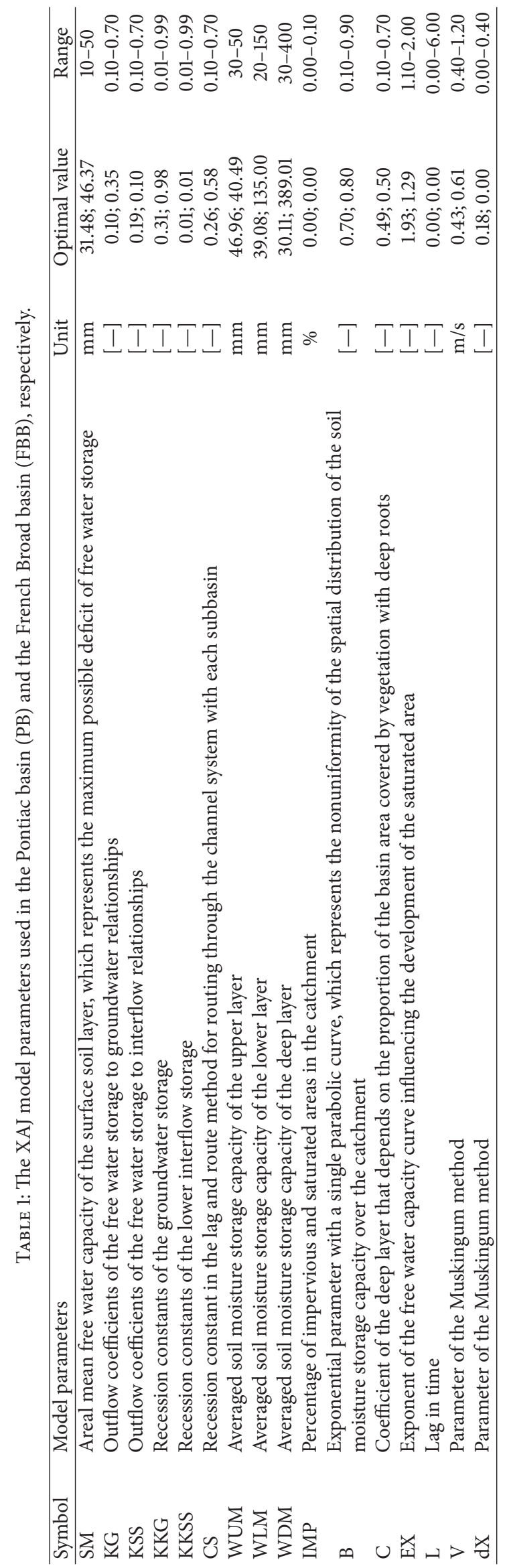




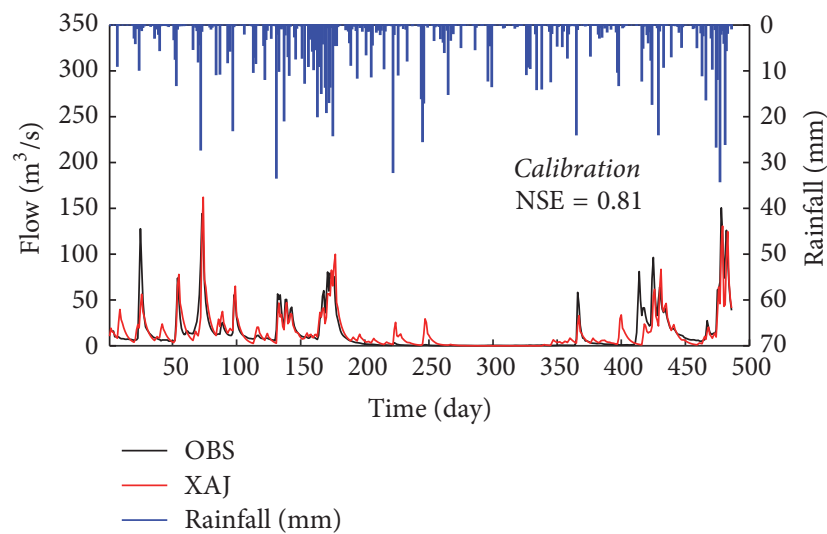

(a)

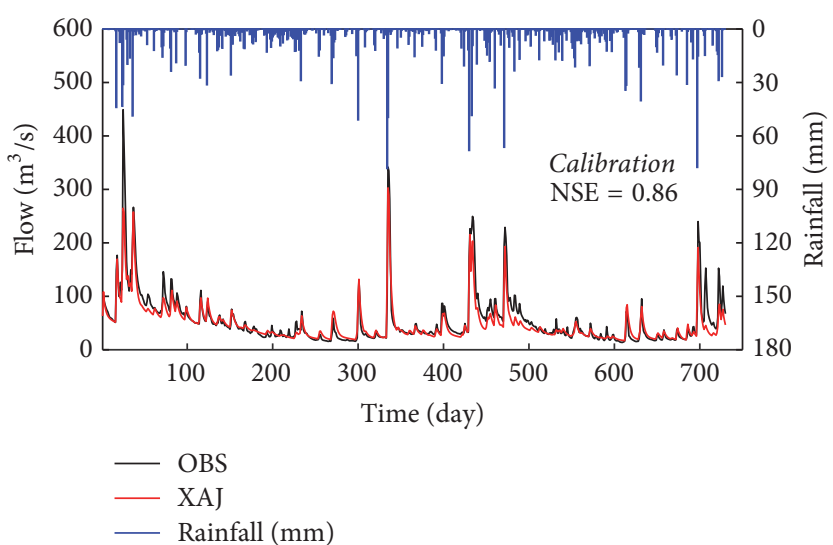

(c)

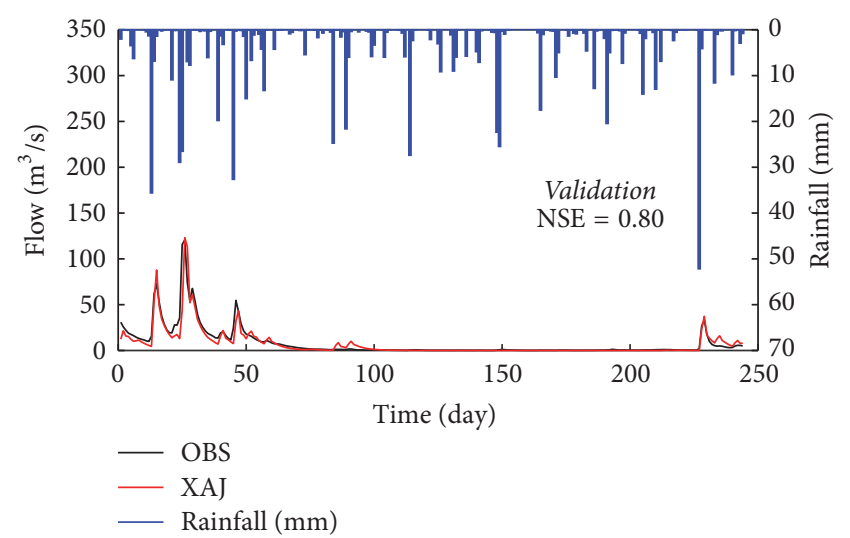

(b)

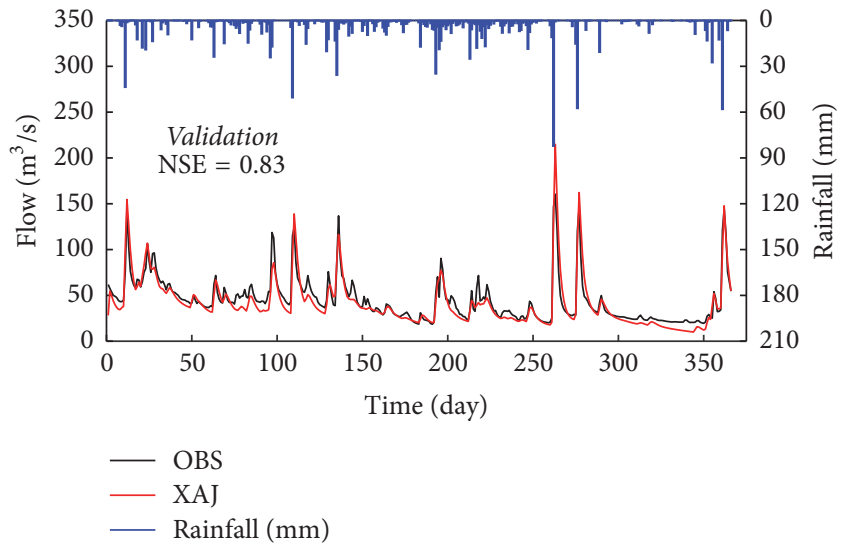

(d)

FIGURE 3: Daily rainfall and flow time series during the calibration and validation with the simulated hydrographs from the XAJ model in PB ((a), (b)) and in FBB ((c), (d)).

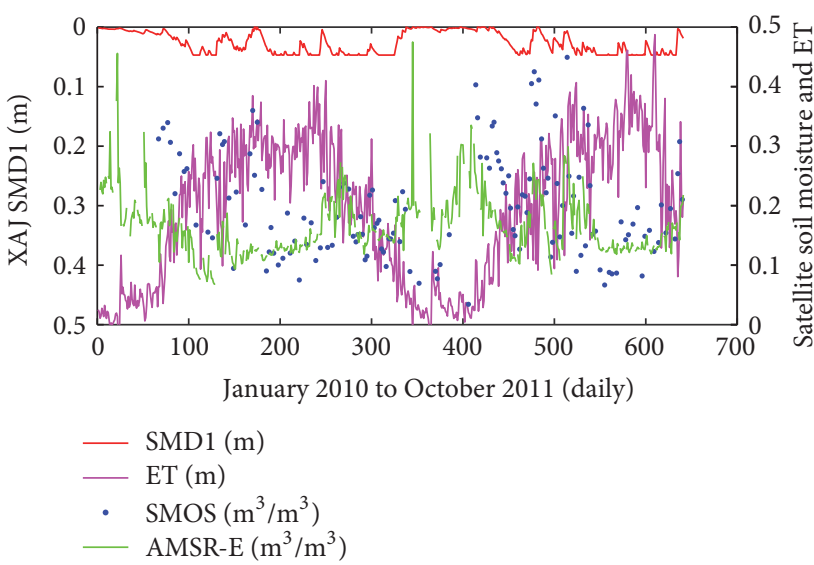

(a)

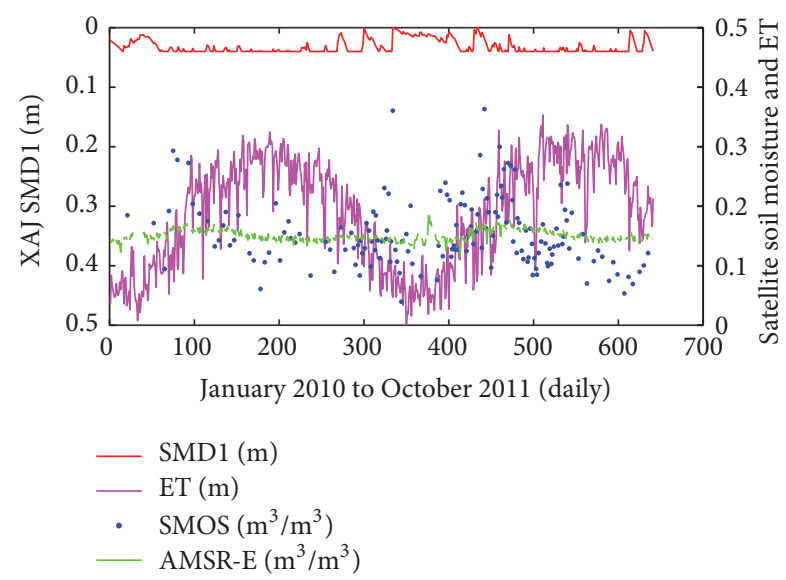

(b)

Figure 4: Comparisons among actual ET, SMD1, SMOS, and AMSR-E for PB (a) and for FBB (b); ET shown here is scaled down to 1/40 of its original value.

series plots of soil moisture demonstrate a high variability with seasons and follow a strong seasonal cycle, with pinnacles normally occurring in winter (January and February) where ET is at the lowest amount. On the other hand, the high temperature and increased ET during summer time (AprilSeptember) lead to an overall drier surface soil. Furthermore, it can be seen that, due to frozen soil, SMOS is not able to provide valid measurements until late February; this is clearly 


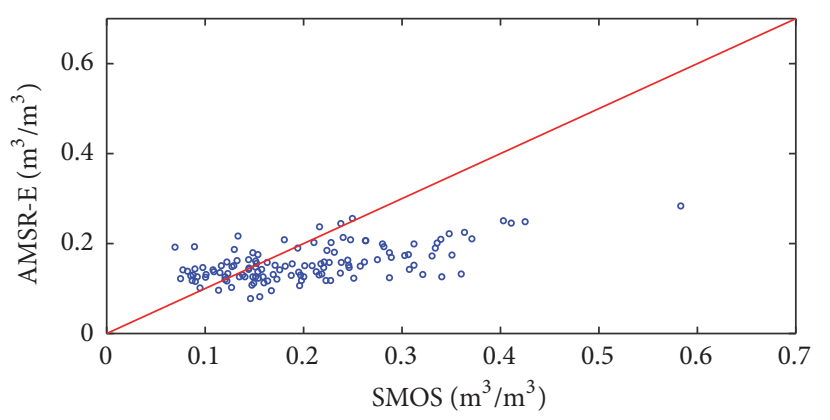

(a)

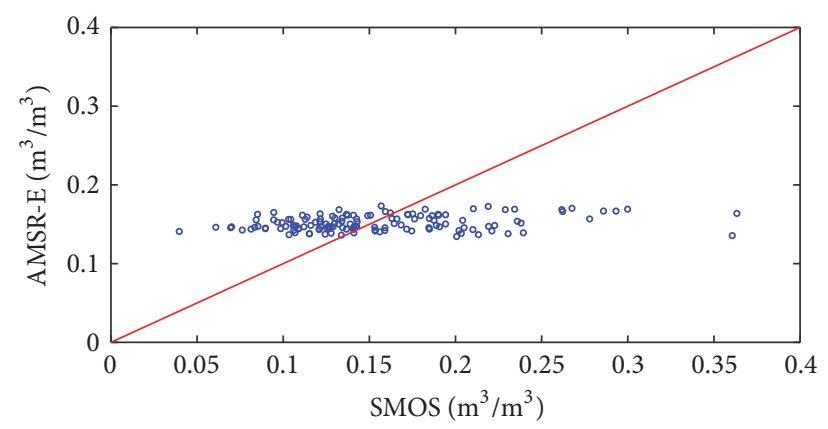

(b)

FIgURE 5: Comparisons between AMSR-E and SMOS: (a) PB with correlation coefficient calculated as $r=0.60$ and (b) FBB with $r=0.29$.

an issue, which has been reported in previous studies [60, 61]. For XAJ simulated result, ET can lead to a significant SMD1 (i.e., soil is near to the wilting point) when there is less rainfall. On the other hand, when ET rates are low while rainfall wets up the soil profile, a surging graph can be obtained in SMD1.

The FBB is located in a densely covered forest region and is subject to high-intensity rainfall events. Generally speaking, the seasonal dynamic is reproduced by the SMOS retrievals, while AMSR-E product stays almost the same (fluctuating around $0.15 \mathrm{~m}^{3} / \mathrm{m}^{3}$ ) during the whole monitoring period. As a result, there is a much wider range of values in the SMOS product than in the AMSR-E one. Furthermore the successive rainfall events are not well captured by both products (refer to Figure 3 for the rainfall plot). For the XAJ simulated result, the SMD1 is significantly decreased (soil moisture reaching the field capacity) when ET is small and rainfall amount is intense, especially during the winter season. Contrarily, considerable ET and relatively less rainfall lead to increasing SMD1 during the summer season. Generally speaking, there is a good agreement on soil moisture temporal dynamics between SMD1 and SMOS. However, AMSR-E dataset demonstrates a rather poor performance.

In addition to the time series plots, the correlations between SMOS and AMSR-E have been explored and plotted for the two study areas (Figure 5). Over $\mathrm{PB}$, it is clear to see that the values of AMSR-E soil moisture $\left(\sim 0.1-0.3 \mathrm{~m}^{3} / \mathrm{m}^{3}\right)$ are evidently smaller than the SMOS observations $(\sim 0.1-$ $0.6 \mathrm{~m}^{3} / \mathrm{m}^{3}$ ), with a correlation coefficient at $r=0.60$. For $\mathrm{FBB}$, the SMOS measurements can range between 0.05 and $0.4 \mathrm{~m}^{3} / \mathrm{m}^{3}$ while AMSR-E datasets stay at almost the same level throughout, with a low correlation coefficient obtained $(r=0.29)$. These results demonstrate that there is a much better agreement of soil moisture measurements between SMOS and AMSR-E in the cropland.

\subsection{Hydrological SMD Simulations, Using SMOS and AMSR-E}

4.3.1. Approach Based on Whole Year Data. This approach shows a more direct comparison between the overall performance of SMOS and AMSR-E datasets against the XAJ SMD1 as the target. The calibration and validation datasets are selected from two parts. In each month, two-thirds of the data are chosen as calibration and the other third as validation, so that both calibration and validation are representative of all the seasons [7]. In this approach, the linear fittings (leastsquares fitting) are evaluated with the equations shown in Figure 6. The goodness of fit is indicated by NSE and RMSE. To further check the linearity between SMD1 and soil moisture products (SMOS and AMSR-E), the $r_{\mathrm{sp}}$ and $r$ correlation statistics between them are calculated.

For the cropland PB, although both soil moisture products show robust correlations with the benchmark SMD1 $(r>0.5)$, the performance of SMOS surpasses AMSR-E during both calibration and validation periods. This could be explained by the relatively longer wavelength of L-band $(\sim 21 \mathrm{~cm})$ than the X-band $(\sim 2.8 \mathrm{~cm})$, so that the impact from crop cover is significantly less for SMOS. The similar results of the calculated correlation statistics $\left(r\right.$ and $\left.r_{\mathrm{sp}}\right)$ reveal that there is no strong nonlinearity for both SMOS and AMSR-E products; hence the linear fitting method used here is suitable.

Over FBB (forest), the similar results between $r$ and $r_{\mathrm{sp}}$ indicate that the linear algorithm is appropriate. However the performance of both products is very poor, especially with the correlation coefficients only at $r=-0.13$ for SMOS and $r=0.15$ for AMSR-E, respectively. Therefore a $t$-test is further implemented to examine the significance of the calculated correlations. The $t$ values for SMOS and AMSR-E are generated as -1.17 and 1.41 , respectively, which fall outside the critical value ranges at $70 \% \mathrm{CI}( \pm 1.04)$ and $80 \% \mathrm{CI}( \pm 1.29)$, respectively. In other words, there exist correlations between SMD1 and SMOS at 70\% CI and between SMD1 and AMSR$\mathrm{E}$ at $80 \% \mathrm{CI}$; however their correlations are rather weak. These poor results could be partially explained by the densely covered canopy in this basin (i.e., covered by a combination of evergreen needleleaf and deciduous broadleaf), where both L-band and X-band microwaves are not able to penetrate.

4.3.2. Approach Based on Temperature for Frozen and Nonfrozen Discriminations. Although satellites struggle to measure soil moisture during the frozen condition, their information contents are not always zero especially during the fuzzy transitional period between the frozen and unfrozen conditions so it is still useful to show the frozen situations. In addition, it is useful to show the performance of satellites soil 


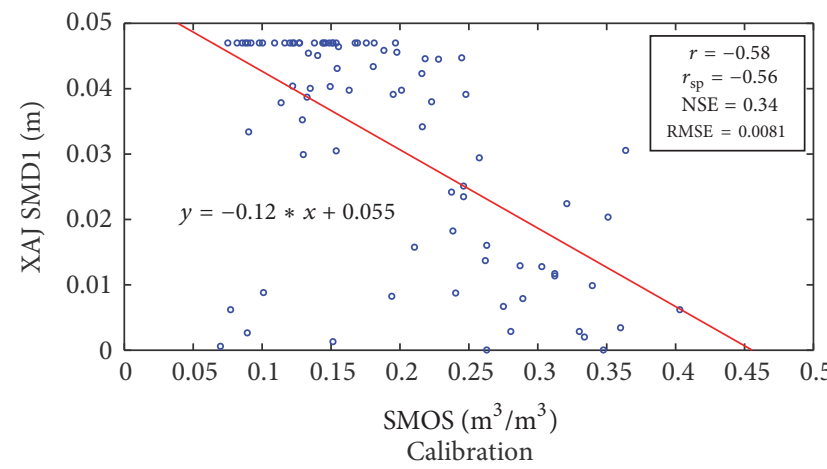

(a)

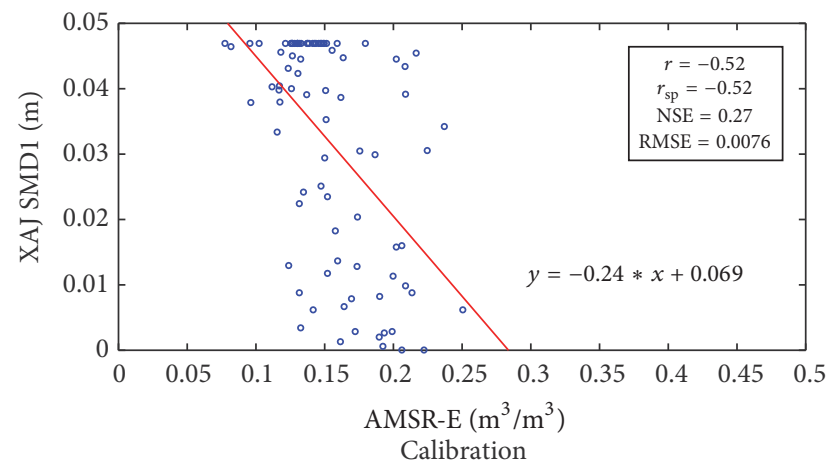

(c)

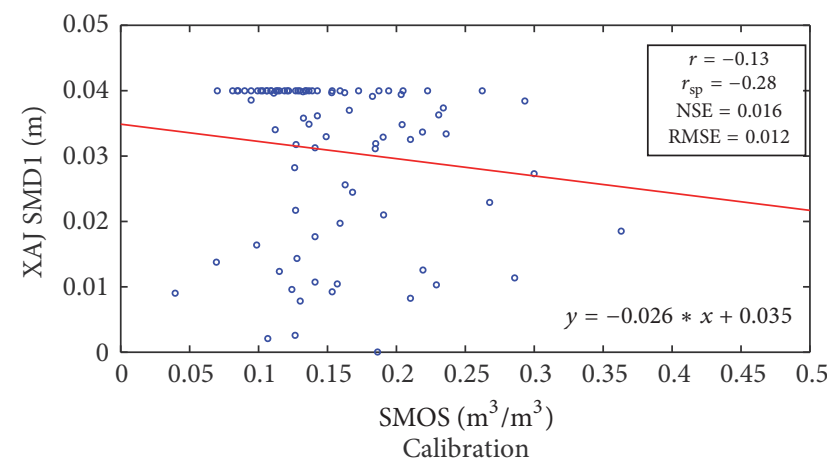

(e)

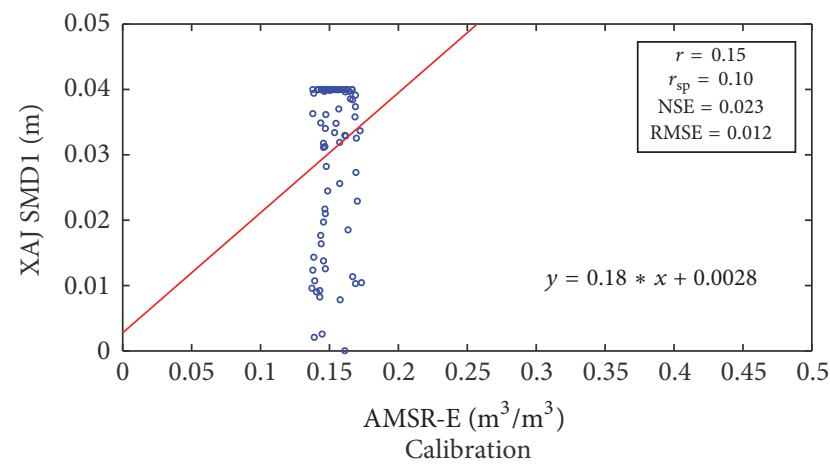

(g)

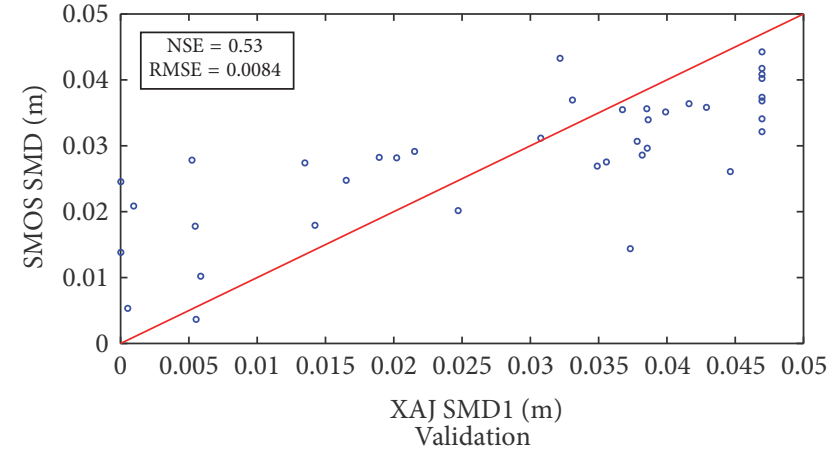

(b)

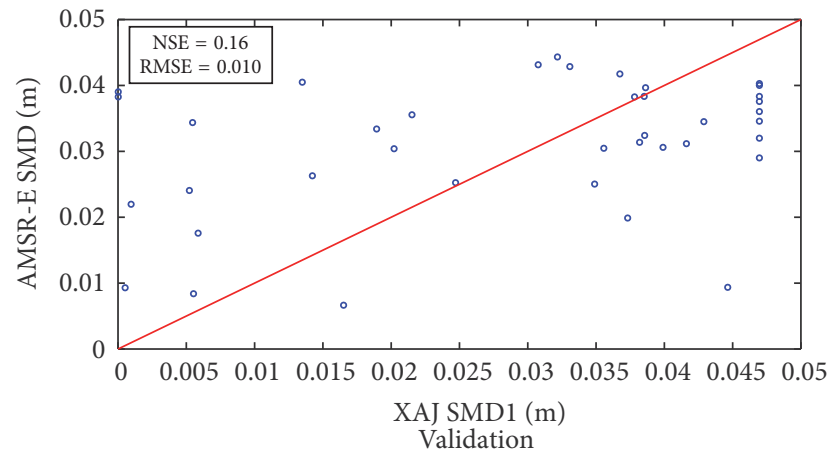

(d)

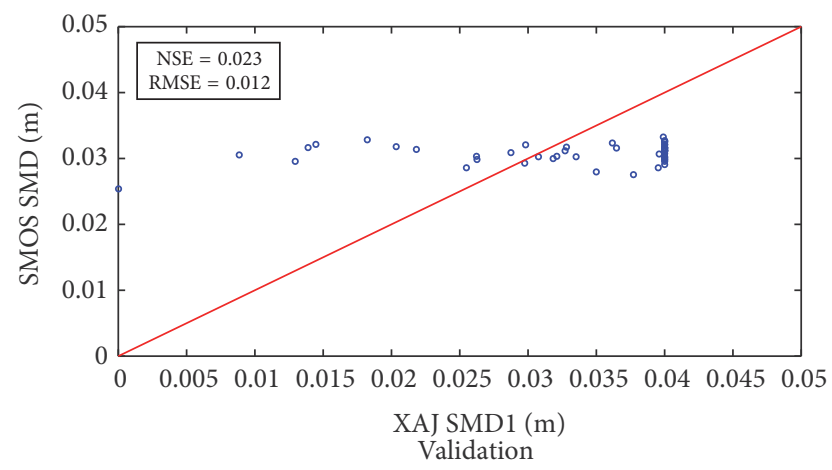

(f)

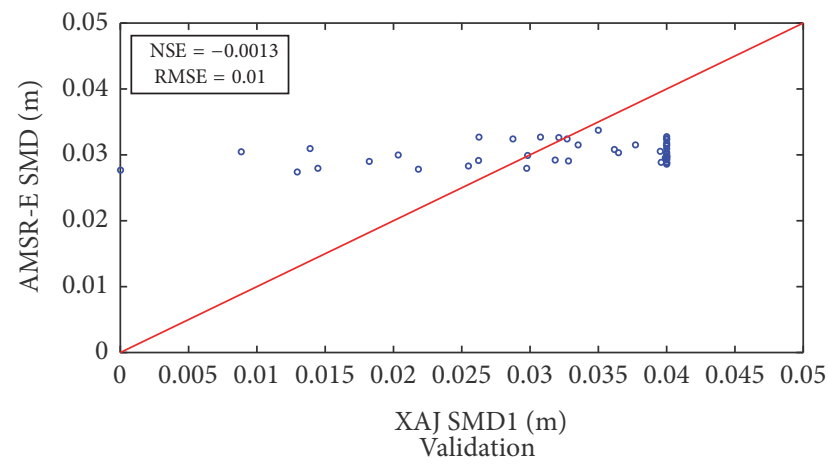

(h)

FIGURE 6: The calibration and validation results using the whole year data. For PB the calibration scatter plots between XAJ SMD1 and SMOS (a) and AMSR-E (c) are presented, and the validation between SMOS derived SMD and original XAJ SMD1 (b) and between AMSR-E derived SMD and original XAJ SMD1 (d) are shown. For FBB the calibration scatter plots between XAJ SMD1 and SMOS (e) and AMSR-E (g) are illustrated, and the validation between SMOS derived SMD and original XAJ SMD1 (f) and between AMSR-E derived SMD and original XAJ SMD1 (h) are shown. It is important to note that, for the calibration, the calculated NSE and RMSE are between the XAJ SMD1 and the satellites' derived SMD during the calibration period; therefore all the RMSEs shown here are in the unit of meter. 
moisture data over the whole time period for completeness so that readers can see the contrasting results. This approach represents a comparison between the simulated SMDs from SMOS and AMSR-E against the XAJ SMD1 calibrated on temperature-based discriminated datasets. In this section, the soil moisture products (SMOS and AMSR-E) are divided into frozen and nonfrozen datasets based on air temperature, where the air temperature threshold is set as $0^{\circ} \mathrm{C}$ in this study [62]. The main reason behind separating frozen and nonfrozen datasets is that satellite soil moisture retrievals can be highly inaccurate under frost soil condition. Although many previous studies [40, 62-64] directly filter out frozen soil observations at the early stage of their investigations, it will still be interesting to see how big is the impact of the frozen soil moisture data on the overall result. Similar to Section 4.3.1, the calibration and validation datasets are firstly divided into two lots, and further from each month twothirds of the data are taken as calibration and the other third as validation. Since similar results are again found between $r$ and $r_{\text {sp }}$ for frozen and nonfrozen conditions, only linear curve fitting is considered here. Generally speaking, all retrieved frozen soil moisture $\left(\sim 0.01-0.016 \mathrm{~m}^{3} / \mathrm{m}^{3}\right)$ is significantly less than that under the nonfrozen condition $\left(\sim 0.05 \mathrm{~m}^{3} / \mathrm{m}^{3}\right)$. This phenomenon could be partially explained by the change of the surface roughness and the emission signal due to the frozen surface, which artificially increasing the brightness temperature, hence reducing soil moisture [65].

For PB (cropland), it is clear to see that temperature is useful in discriminating data into frozen and nonfrozen groups and soil moisture estimation under nonfrozen condition performs remarkably better than that under the frozen condition. By excluding the freezing soil moisture, the performance of the SMOS derived SMD (Figure 7(a)) is improved markedly for both calibration (NSE $=0.66$, RMSE $=0.0073 \mathrm{~m})$ and validation $(\mathrm{NSE}=0.67, \mathrm{RMSE}=0.0068 \mathrm{~m})$ periods. However when combined with the frozen data, the result as expected dropped dramatically (NSE $=0.25$, RMSE $=0.014 \mathrm{~m}$ ). On the other hand, the AMSR-E derived SMD (Figure 7(b)) cannot achieve satisfying results under both frozen and nonfrozen conditions.

For the forest site (FBB), both derived SMDs (SMOS and AMSR-E) exhibit dampened outcomes (Figures 7(c) and 7(d)). Nevertheless slightly better results of RMSE are observed under nonfrozen condition for both derived SMDs, during the validation period. This result reveals that, for the chosen forest area, none of the products (SMOS and AMSRE) is capable of generating good quality SMD information, regardless of temperature conditions.

4.3.3. Approach Based on MODIS NDVI for Denser and Thinner Vegetation Period Discriminations. Studies carried by Carlson et al. [17] and Wang et al. [66] illustrate that there exists a relationship between surface soil moisture and NDVI. Therefore this section presents the comparison results between the derived SMDs from SMOS and AMSR-E against the XAJ SMD1 calibrated on NDVI based discriminated datasets (in another words, to use different algorithms for various vegetation coverage situations). This is because soil moisture under denser vegetation period and thinner vegetation period behave dissimilarly; hence it is possible that more accurate SMD estimation could be gained by making the algorithms separately. Our method using the NDVI as an indication of the density of vegetation coverage is more accurate than the method used in Srivastava et al. [7], who roughly classified the data by seasons (i.e., the denser vegetation season is from March to November, while the thinner vegetation season is from the rest months). It is important to note that the evaluation of this approach is only based on nonfrozen soil moisture datasets. The SMD1 and soil moisture products (SMOS and AMSR-E) are plotted with the MODIS NDVI datasets at the two selected basins in Figure 8. The overall NDVI shows similar fluctuation in pattern with both remotely sensed soil moisture retrievals and SMD1. It is clear that soil moisture peaks (where SMD1 is bottomed) when NDVI decreases to the lowest, because ET is reduced due to blighted crops. Oppositely, less soil moisture values are observed (where SMD1 reaches highest points) during the summer season when NDVI is high, except the AMSR-E retrievals in FBB.

In order to discriminate the soil moisture datasets into denser and thinner vegetation periods, NDVI thresholds of 0.81 and 0.64 are used for $\mathrm{PB}$ and $\mathrm{FBB}$, respectively (i.e., the data with NDVI $\geq$ threshold are classified into the denser vegetation group and the data with NDVI $<$ threshold are classified into the thinner vegetation group). The NDVI threshold is found by using the trial and error method so that the best NSE performance can be achieved hydrologically. Due to the small quantity of datasets in both denser and thinner vegetation periods, the leave-one-out cross-validation method is carried out instead, which is useful in reducing the overfitting problem [67]. As discussed in previous sections, only linear curve fitting is considered here.

As presented in Figure 9 and Table 2, for the cropland (PB), the comparisons of the derived SMDs (from SMOS and AMSR-E) with XAJ SMD1 demonstrate higher degrees of goodness of fit with vegetation coverage based algorithms. The validation of SMOS derived SMD has improved from $\mathrm{NSE}=0.67$ and RMSE $=0.0068 \mathrm{~m}$ to NSE $=0.74$ and $\mathrm{RMSE}$ $=0.0059 \mathrm{~m}$, while the validation result of AMSR-E derived SMD has increased greatly from NSE $=0.14$ and RMSE $=$ $0.0075 \mathrm{~m}$ to NSE $=0.58$ and $\mathrm{RMSE}=0.0066 \mathrm{~m}$. This large improvement in the NSE for AMSR-E is caused by the fact that the NDVI threshold separates the data points (above 0.81 NDVI) of AMSR-E, which shows a limited sensitivity to soil moisture as a result of the restricted penetration capacity and dense vegetation cover (as seen from Figure 8(a)). Furthermore, in terms of RMSE, the thinner vegetation period soil moisture datasets perform better for both SMOS and AMSR$\mathrm{E}$; nevertheless it is worse if NSE is considered for the AMSRE case. It is believed that the RMSE should be considered here because, theoretically, denser canopy would result in poorer satellite soil moisture measurements [7]. Generally speaking, the performance of SMOS in the cropland is better than that with the AMSR-E product based on both NSE and RMSE indicators.

Over the FBB (forest), this NDVI based approach is not a success and therefore only the statistical results are shown in 

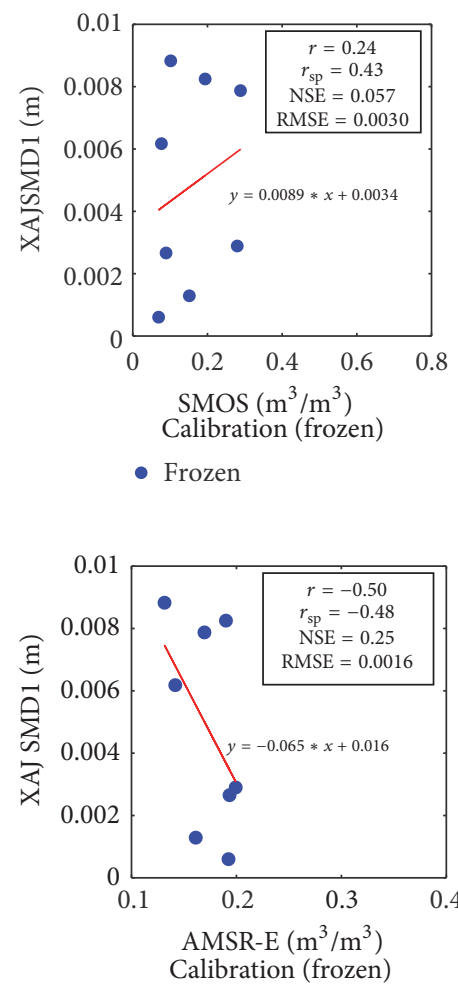

- Frozen

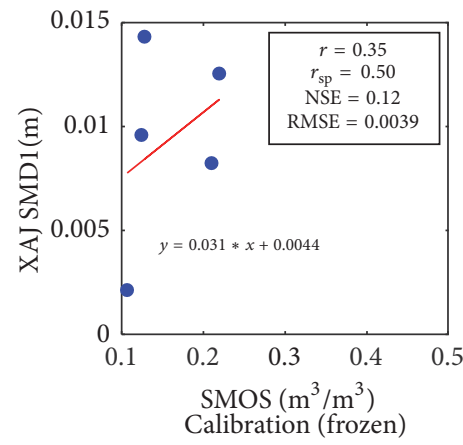

- Frozen

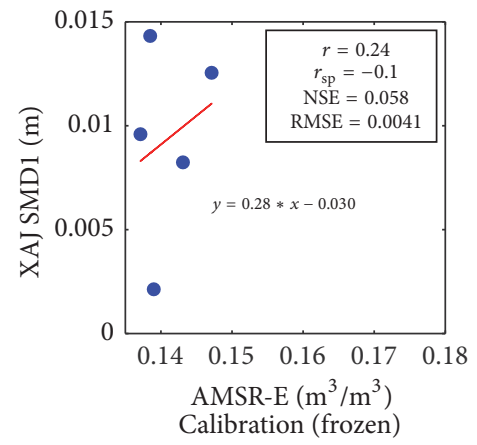

- Frozen

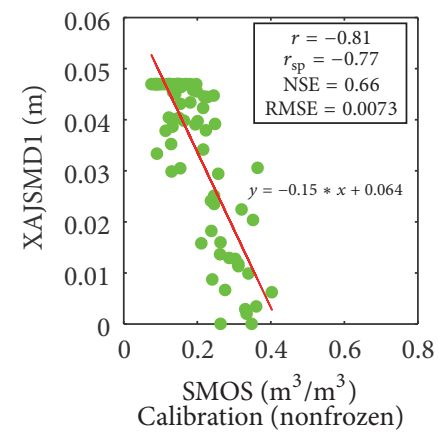

- Nonfrozen

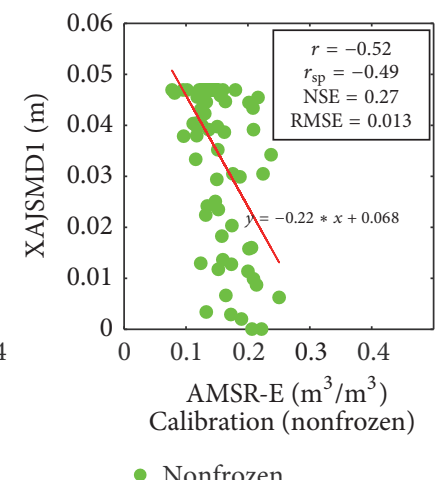

(b)

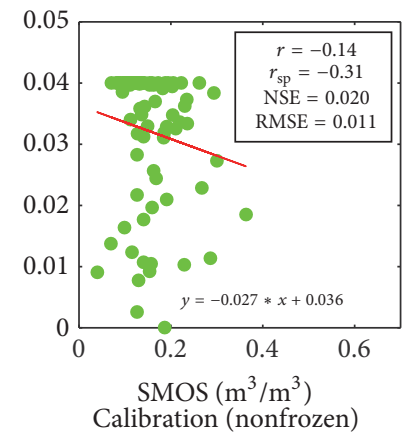

- Nonfrozen

(c)

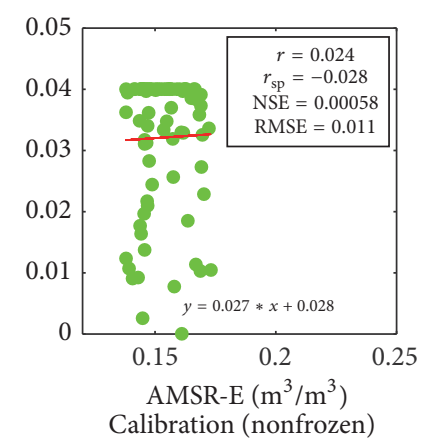

- Nonfrozen
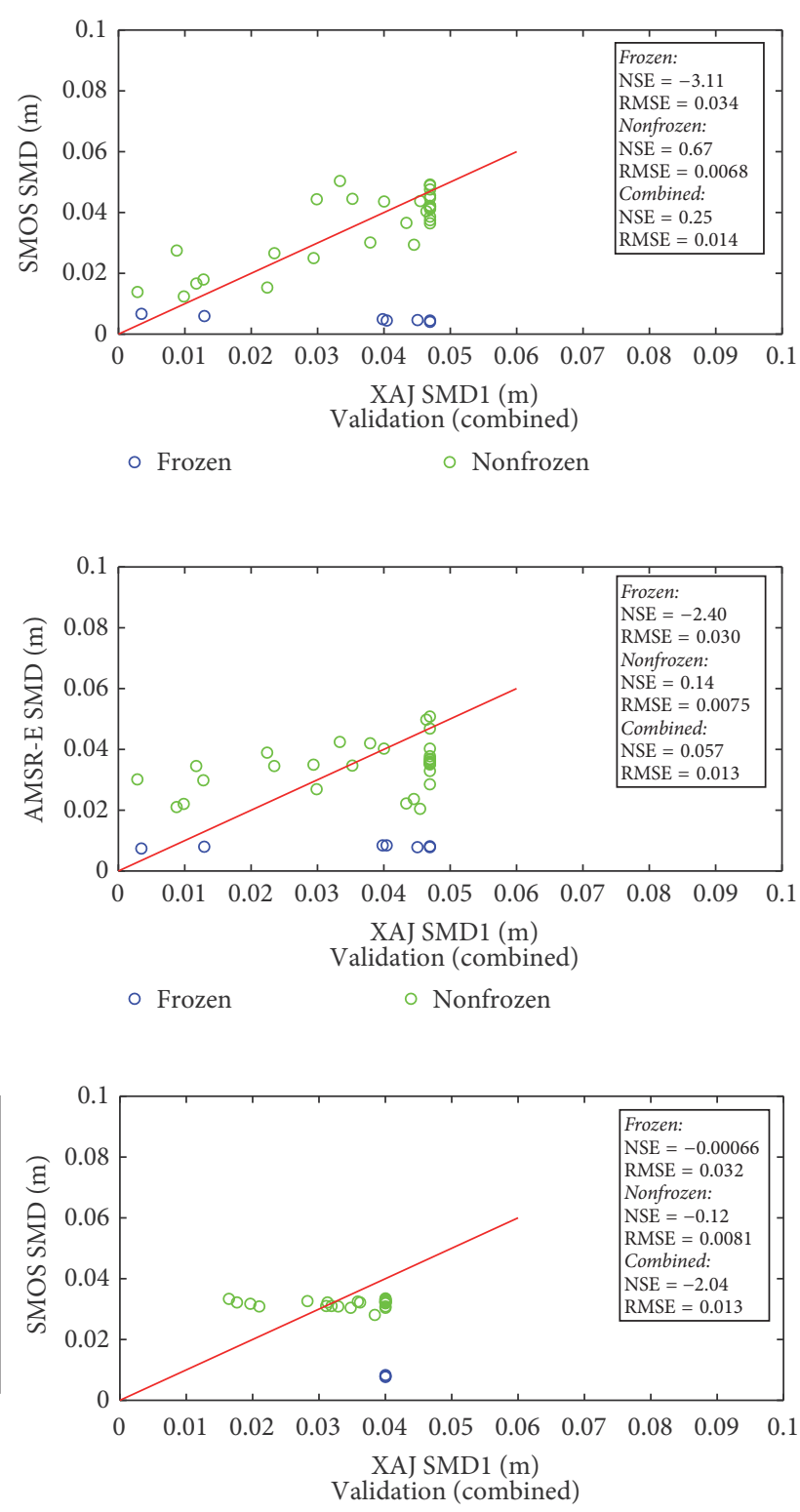

○ Frozen

- Nonfrozen

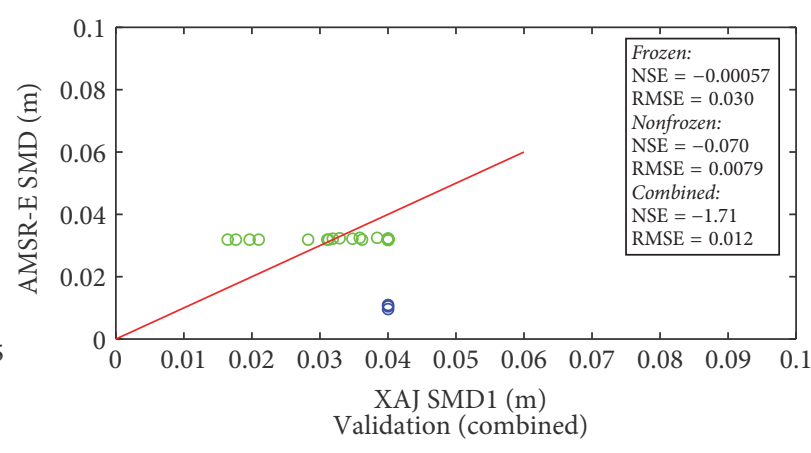

○ Frozen

(d)

FIGURE 7: The calibration and validation results using temperature-based discrimination approach. For PB the performance of SMOS derived SMD (a) and AMSR-E derived SMD (b) are presented. For FBB the performance of SMOS derived SMD (c) and AMSR-E derived SMD (d) is shown. It is important to note that, for the calibration, the calculated NSE and RMSE are between the XAJ SMD1 and the satellites' derived SMD during the calibration period; therefore all the RMSEs shown here are in the unit of meter. 


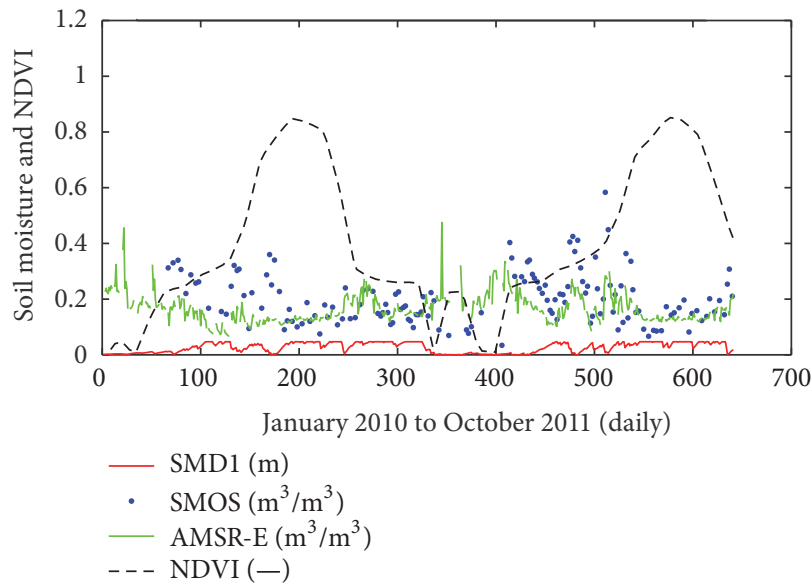

(a)

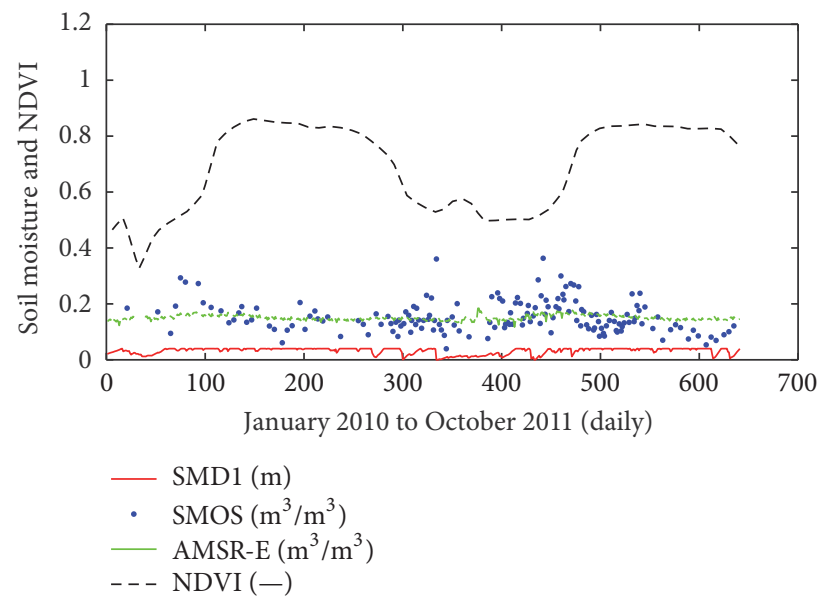

(b)

FIGURE 8: The time series plots of soil moisture products (SMOS and AMSR-E) and XAJ SMD1 with MODIS NDVI for the two selected basins: (a) PB and (b) FBB. The time step for soil moisture is Julian day and the one for NDVI is every 16 days.

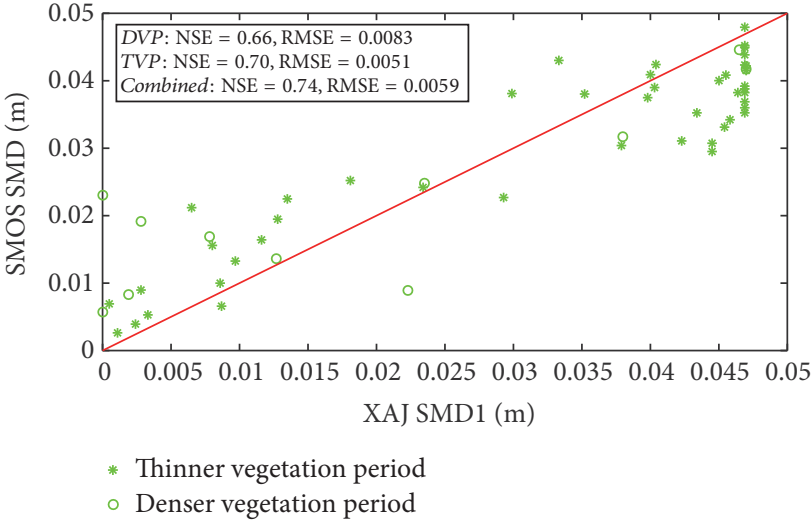

(a)

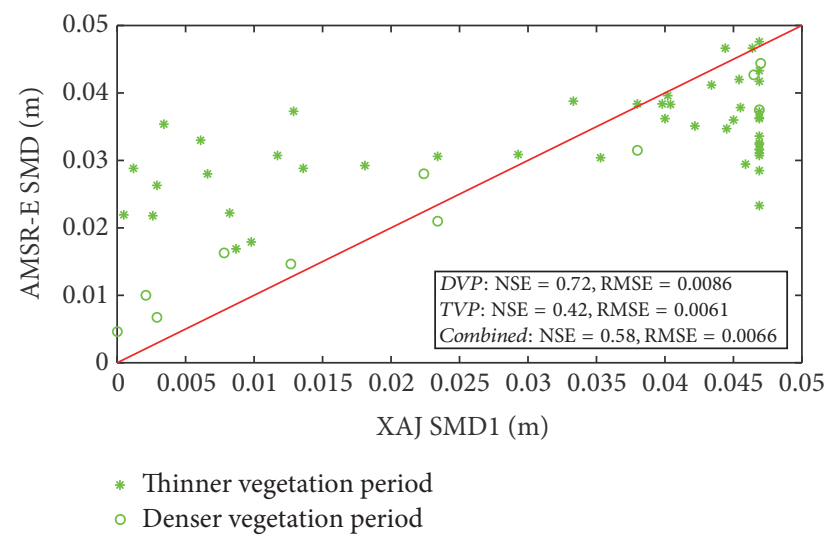

(b)

FIgURE 9: For PB basin, leave-one-out cross-validation results of SMDs derived from the two satellite soil moisture products (SMOS and AMSR-E) against XAJ SMD1: (a) SMOS and (b) AMSR-E. DVP stands for denser vegetation period and TVP means thinner vegetation period. It is noted that all RMSEs shown here are in the unit of meter.

Table 2. The thinner vegetation period soil moisture dataset is not improved as expected. This is because FBB is covered with a combination of evergreen needleleaf and deciduous broadleaf [31], which means the basin is almost always covered with dense canopies. Nevertheless some good results have been reported over other forest types, such as over tropical forest [68], spruce forest [4], and boreal forests [69]. In addition to the vegetation impact, the maritime temperate climate may also cause the poor performance, because it can lead to less seasonality and variations in the soil moisture [7].

\section{Discussion}

In this study there are several points that need to be discussed.

First. The performance of SMOS in the cropland is better than AMSR-E based on both NSE and RMSE indicators. Similar results were discovered in Al-Yaari et al. [40] and
Wagner et al. [62]. However it should be pointed out that the SMOS product is significantly less available than AMSR-E's, especially on rainy days [70]. Frequent revisit time is important for hydrological applications, especially to obtain adequate measurements of surface wetting and drying between precipitation events [22]. Hence it might be valuable to use data fusion technology between SMOS and AMSR-E for a wider range of hydrological applications.

Second. Although the combined "denser vegetation period" and "thinner vegetation period" algorithms improve the SMD derivation accuracy for both satellite soil moisture products in the $\mathrm{PB}$, further improvement is still needed. Due to the poor spatial resolution from the satellites microwave bands, higher spatial resolutions of soil moisture could be realized by utilizing downscaling methods $[6,71]$, such as by using the soil moisture outputs from land surface models (e.g., Noah and Variable Infiltration Capacity (VIC) models), 
TABLE 2: Performance statistics of individual algorithm under each approach, as well as the performance of the combined algorithm under each approach. DVP stands for denser vegetation period and TVP means thinner vegetation period.

\begin{tabular}{|c|c|c|c|c|c|c|}
\hline \multirow{2}{*}{ Basins } & \multirow{2}{*}{ Approaches } & \multirow{2}{*}{ Soil moisture products } & \multicolumn{2}{|c|}{ Validation (individual algorithm) } & \multicolumn{2}{|c|}{ Validation (combined algorithm) } \\
\hline & & & NSE & RMSE (m) & NSE & RMSE (m) \\
\hline \multirow{10}{*}{$\begin{array}{l}\text { PB (middle of } \\
\text { US) }\end{array}$} & \multirow{2}{*}{ Whole year } & SMOS (all) & - & - & 0.53 & 0.0084 \\
\hline & & AMSR-E (all) & - & - & 0.16 & 0.010 \\
\hline & \multirow{4}{*}{ Temperature-based } & SMOS (frozen) & -3.11 & 0.034 & \multirow{2}{*}{0.25} & \multirow{2}{*}{0.014} \\
\hline & & SMOS (nonfrozen) & 0.67 & 0.0068 & & \\
\hline & & AMSR-E (frozen) & -2.40 & 0.030 & \multirow{2}{*}{0.057} & \multirow{2}{*}{0.013} \\
\hline & & AMSR-E (nonfrozen) & 0.14 & 0.0075 & & \\
\hline & \multirow{4}{*}{ NDVI based } & SMOS (DVP) & 0.66 & 0.0083 & \multirow{2}{*}{0.74} & \multirow{2}{*}{0.0059} \\
\hline & & SMOS (TVP) & 0.70 & 0.0051 & & \\
\hline & & AMSR-E (DVP) & 0.72 & 0.0086 & \multirow{2}{*}{0.58} & \multirow{2}{*}{0.0066} \\
\hline & & AMSR-E (TVP) & 0.42 & 0.0061 & & \\
\hline \multirow{10}{*}{$\begin{array}{l}\text { FBB (east of } \\
\text { US) }\end{array}$} & \multirow{2}{*}{ Whole year } & SMOS (all) & - & - & 0.023 & 0.012 \\
\hline & & AMSR-E (all) & - & - & -0.0013 & 0.010 \\
\hline & \multirow{4}{*}{ Temperature-based } & SMOS (frozen) & -0.00066 & 0.032 & \multirow{2}{*}{-2.04} & \multirow{2}{*}{0.013} \\
\hline & & SMOS (nonfrozen) & -0.12 & 0.0081 & & \\
\hline & & AMSR-E (frozen) & -0.00057 & 0.030 & \multirow{2}{*}{-1.71} & \multirow{2}{*}{0.012} \\
\hline & & AMSR-E (nonfrozen) & -0.070 & 0.0079 & & \\
\hline & \multirow{4}{*}{ NDVI based } & SMOS (DVP) & 0.12 & 0.012 & \multirow{2}{*}{0.16} & \multirow{2}{*}{0.011} \\
\hline & & SMOS (TVP) & -0.059 & 0.019 & & \\
\hline & & AMSR-E (DVP) & -0.073 & 0.015 & \multirow{2}{*}{0.084} & \multirow{2}{*}{0.012} \\
\hline & & AMSR-E (TVP) & 0.033 & 0.018 & & \\
\hline
\end{tabular}

distributed hydrological models, and other bands of remote sensing (e.g., thermal infrared). Moreover the linear NDVI based method performs rather well for the cropland over hot summer continental climates. Therefore this approach could be generalized for ungauged basins by applying the regionalization concept as devoted to the index flood $[72,73]$.

Third. Other hydrological indices such as Catchment Wetness Index (CWI) can also be used to compare with the satellite soil moisture. However CWI is a lumped soil moisture indicator covering the whole root zone. Therefore it is not directly useful in a multilayer conceptual hydrological model such as XAJ. As a result choosing the right hydrological state variable to link with the satellite soil moisture observations as described in this study is important.

Fourth. Ideally we hope that the satellite footprint is the same size as the catchment area; however, it is not always possible to achieve this with existing sensors. If the satellite footprint is smaller than the catchment, then it is not an issue because the aggregation of the satellite pixels within the catchment can be matched to the catchment area. On the other hand, if the satellite footprint is larger than the catchment area, this could be a problem because if the soil moisture is unevenly distributed, the catchment soil moisture could be very different to the average soil moisture as measured by the large satellite footprint (for example, if the catchment is located in the drier part of the footprint, its soil moisture would be overestimated, whereas the opposite would happen for the wetter part of the footprint) [28]. A better way to handle this is through spatial downscaling using data fusion techniques (e.g., to combine coarse microwave data with fine surface temperature data), which should be explored in the future.

Finally although we desire to include more satellite products with extended time period and over a larger number of study basins, it is not feasible to explore all possible cases within one study due to limited time and resource, as well as the restricted overlap in time between different soil moisture products. Furthermore the two catchments studied here represent the two extreme conditions of the hydrological catchment land cover types, so they act like an envelope to cover a wide range of hydrological catchments. The reason for excluding the bare soil situation in this study is because for most operational hydrological models, such as XAJ, they are not designed to be used in arid areas. This study will stimulate further studies on satellite remote sensing of soil moisture in the hydrological community.

\section{Conclusions}

This study demonstrates that the linear algorithm has its capability in converting remotely sensed soil moisture into 
hydrological SMD. Both SMOS and AMSR-E perform better over the cropland under the hot summer continental climate than the forest basin under the maritime temperate climate. In addition, the performance is further improved by removing frozen soil moisture datasets using the temperature information from the local meteorological stations. Since the canopy attenuates microwave, the MODIS NDVI datasets are deployed to further discriminate nonfrozen data into the denser vegetation period and the thinner vegetation period. This approach shows even better performance than the approach without considering the density of the vegetation coverage factor. Overall SMOS outperforms AMSR-E in most cases, except during the denser vegetation period. As presented in Discussion, although many studies have reported similar results as explored in this paper, there are other studies in which AMSR-E soil moisture products are better than SMOS's. Therefore the results are mixed in various comparisons and indicate that more studies in this area are required to find out when and where the SMOS product is better than the AMSR-E's and vice versa. On the other hand, the SMOS product is significantly less available than AMSRE, especially on rainy days. Therefore a possible data fusion method could be implemented between the SMOS and the AMSR-E for a more effective application in hydrological modelling.

\section{Competing Interests}

The authors declare that they have no competing interests.

\section{Acknowledgments}

This study is supported by Resilient Economy and Society by Integrated SysTems modelling (RESIST), Newton Fund via Natural Environment Research Council (NERC), and Economic and Social Research Council (ESRC) (NE/N012143/1).

\section{References}

[1] D. Aubert, C. Loumagne, and L. Oudin, "Sequential assimilation of soil moisture and streamflow data in a conceptual rainfall-runoff model," Journal of Hydrology, vol. 280, no. 1-4, pp. 145-161, 2003.

[2] J. C. Refsgaard, "Validation and intercomparison of different updating procedures for real-time forecasting," Nordic Hydrology, vol. 28, no. 2, pp. 65-84, 1997.

[3] C. Ottlé and D. Vidal-Madjar, "Assimilation of soil moisture inferred from infrared remote sensing in a hydrological model over the HAPEX-MOBILHY region," Journal of Hydrology, vol. 158, no. 3-4, pp. 241-264, 1994.

[4] M.-E. Ridler, H. Madsen, S. Stisen, S. Bircher, and R. Fensholt, "Assimilation of SMOS-derived soil moisture in a fully integrated hydrological and soil-vegetation-atmosphere transfer model in Western Denmark," Water Resources Research, vol. 50, no. 11, pp. 8962-8981, 2014.

[5] P. K. Srivastava, D. Han, M. A. Rico-Ramirez, P. O’Neill, T. Islam, and M. Gupta, "Assessment of SMOS soil moisture retrieval parameters using tau-omega algorithms for soil moisture deficit estimation," Journal of Hydrology, vol. 519, pp. 574587, 2014.
[6] P. K. Srivastava, D. Han, M. A. Rico-Ramirez, D. Al-Shrafany, and T. Islam, "Data Fusion techniques for improving soil moisture deficit using SMOS satellite and WRF-NOAH land surface model," Water Resources Management, vol. 27, no. 15, pp. 5069-5087, 2013.

[7] P. K. Srivastava, D. Han, M. A. Rico Ramirez, and T. Islam, "Appraisal of SMOS soil moisture at a catchment scale in a temperate maritime climate," Journal of Hydrology, vol. 498, pp. 292-304, 2013

[8] W. Wagner, V. Naeimi, K. Scipal, R. Jeu, and J. MartínezFernández, "Soil moisture from operational meteorological satellites," Hydrogeology Journal, vol. 15, no. 1, pp. 121-131, 2007.

[9] N. Wanders, D. Karssenberg, A. De Roo, S. M. De Jong, and M. F. P. Bierkens, "The suitability of remotely sensed soil moisture for improving operational flood forecasting," Hydrology and Earth System Sciences, vol. 18, no. 6, pp. 2343-2357, 2014.

[10] N. Wanders, D. Karssenberg, M. Bierkens et al., "Observation uncertainty of satellite soil moisture products determined with physically-based modeling," Remote Sensing of Environment, vol. 127, pp. 341-356, 2012.

[11] D. Al-Shrafany, M. A. Rico-Ramirez, D. Han, and M. Bray, "Comparative assessment of soil moisture estimation from land surface model and satellite remote sensing based on catchment water balance," Meteorological Applications, vol. 21, no. 3, pp. 521-534, 2014.

[12] E. T. Engman and R. J. Gurney, Remote Sensing in Hydrology, Chapman and Hall, 1991.

[13] J. P. Walker, G. R. Willgoose, and J. D. Kalma, "In situ measurement of soil moisture: a comparison of techniques," Journal of Hydrology, vol. 293, no. 1-4, pp. 85-99, 2004.

[14] L. Wang and J. J. Qu, "Satellite remote sensing applications for surface soil moisture monitoring: a review," Frontiers of Earth Science in China, vol. 3, no. 2, pp. 237-247, 2009.

[15] E. T. Engman and N. Chauhan, "Status of microwave soil moisture measurements with remote sensing," Remote Sensing of Environment, vol. 51, no. 1, pp. 189-198, 1995.

[16] T. N. Carlson, K. Dodd Joseph, G. Benjamin Stanley, and N. Cooper James, "Satellite estimation of the surface energy balance, moisture availability and thermal inertia," Journal of Applied Meteorology, vol. 20, no. 1, pp. 67-87, 1981.

[17] T. N. Carlson, R. R. Gillies, and E. M. Perry, "A method to make use of thermal infrared temperature and NDVI measurements to infer surface soil water content and fractional vegetation cover," Remote Sensing Reviews, vol. 9, no. 1-2, pp. 161-173, 1994.

[18] P. J. Curran, "A photographic method for the recording of polarised visible light for soil surface moisture indications," Remote Sensing of Environment, vol. 7, no. 4, pp. 305-322, 1978.

[19] D. Entekhabi, E. G. Njoku, P. E. O’Neill et al., "The soil moisture active passive (SMAP) mission," Proceedings of the IEEE, vol. 98, no. 5, pp. 704-716, 2010.

[20] Y. H. Kerr, P. Waldteufel, J.-P. Wigneron, J. Martinuzzi, J. Font, and M. Berger, "Soil moisture retrieval from space: the Soil Moisture and Ocean Salinity (SMOS) mission," IEEE Transactions on Geoscience and Remote Sensing, vol. 39, no. 8, pp. 1729-1735, 2001.

[21] R. H. Reichle, R. D. Koster, P. Liu, S. P. P. Mahanama, E. G. Njoku, and M. Owe, "Comparison and assimilation of global soil moisture retrievals from the Advanced Microwave Scanning Radiometer for the Earth Observing System (AMSR-E) and the Scanning Multichannel Microwave Radiometer (SMMR)," Journal of Geophysical Research: Atmospheres (1984-2012), vol. 112, no. 9, 2007. 
[22] E. G. Njoku, T. J. Jackson, V. Lakshmi, T. K. Chan, and S. V. Nghiem, "Soil moisture retrieval from AMSR-E," IEEE Transactions on Geoscience and Remote Sensing, vol. 41, no. 2, pp. 215-229, 2003.

[23] E. G. Njoku and S. K. Chan, "Vegetation and surface roughness effects on AMSR-E land observations," Remote Sensing of Environment, vol. 100, no. 2, pp. 190-199, 2006.

[24] T. Lacava, P. Matgen, L. Brocca et al., "A first assessment of the SMOS soil moisture product with in situ and modeled data in Italy and Luxembourg," IEEE Transactions on Geoscience and Remote Sensing, vol. 50, no. 5, pp. 1612-1622, 2012.

[25] K. Rötzer, C. Montzka, H. Bogena et al., "Catchment scale validation of SMOS and ASCAT soil moisture products using hydrological modeling and temporal stability analysis," Journal of Hydrology, vol. 519, pp. 934-946, 2014.

[26] L. Zhuo, Q. Dai, and D. Han, "Evaluation of SMOS soil moisture retrievals over the central United States for hydrometeorological application," Physics and Chemistry of the Earth, vol. 83-84, pp. 146-155, 2015.

[27] L. Zhuo, Q. Dai, T. Islam, and D. Han, "Error distribution modelling of satellite soil moisture measurements for hydrological applications," Hydrological Processes, vol. 30, no. 13, pp. $2223-$ 2236, 2016.

[28] L. Zhuo and D. Han, "Could operational hydrological models be made compatible with satellite soil moisture observations?" Hydrological Processes, vol. 30, no. 10, pp. 1637-1648, 2016.

[29] M. C. Peel, B. L. Finlayson, and T. A. McMahon, "Updated world map of the Köppen-Geiger climate classification," Hydrology and Earth System Sciences, vol. 11, no. 5, pp. 1633-1644, 2007.

[30] E. Bartholomé and A. S. Belward, "GLC2000: a new approach to global land cover mapping from earth observation data," International Journal of Remote Sensing, vol. 26, no. 9, pp. 19591977, 2005.

[31] M. Hansen, R. DeFries, J. R. G. Townshend, and R. Sohlberg, "UMD global land cover classification," in 1 Kilometer, pp. 1981-1994, Department of Geography, University of Maryland, College Park, Md, USA, 1998.

[32] R. W. Webb, C. E. Rosenzweig, and E. R. Levine, Global Soil Texture and Derived Water-Holding Capacities (Webb et al.). Data Set, Oak Ridge National Laboratory Distributed Active Archive Center, Oak Ridge, Tenn, USA, 2000, http://www .daac.ornl.gov.

[33] Q. Duan, J. Schaake, V. Andréassian et al., "Model Parameter Estimation Experiment (MOPEX): an overview of science strategy and major results from the second and third workshops," Journal of Hydrology, vol. 320, no. 1-2, pp. 3-17, 2006.

[34] K. E. Mitchell, D. Lohmann, P. R. Houser et al., "The multiinstitution North American Land Data Assimilation System (NLDAS): utilizing multiple GCIP products and partners in a continental distributed hydrological modeling system," Journal of Geophysical Research D: Atmospheres, vol. 109, no. D7, 2004.

[35] NCDC, NOAA National Climatic Data Center, 2015, http:// www.ncdc.noaa.gov/.

[36] Y. H. Kerr, P. Waldteufel, J.-P. Wigneron et al., "The SMOS mission: new tool for monitoring key elements ofthe global water cycle," Proceedings of the IEEE, vol. 98, no. 5, pp. 666-687, 2010.

[37] Y. H. Kerr, P. Waldteufel, P. Richaume et al., "The SMOS soil moisture retrieval algorithm," IEEE Transactions on Geoscience and Remote Sensing, vol. 50, no. 5, pp. 1384-1403, 2012.
[38] BEC-SMOS, "SMOS-BEC ocean and land products description,” 2016, https://cp34-bec.cmima.csic.es/doc/BEC-SMOS-0001 -PD.pdf.

[39] E. Jacquette, A. Al Bitar, A. Mialon et al., "SMOS CATDS level 3 global products over land," in Proceedings of the Remote Sensing for Agriculture, Ecosystems, and Hydrology XII, Toulouse, France, September 2010.

[40] A. Al-Yaari, J.-P. Wigneron, A. Ducharne et al., "Global-scale evaluation of two satellite-based passive microwave soil moisture datasets (SMOS and AMSR-E) with respect to Land Data Assimilation System estimates," Remote Sensing of Environment, vol. 149, pp. 181-195, 2014.

[41] T. J. Jackson, "Profile soil moisture from surface measurements," Journal of the Irrigation and Drainage Division, American Society of Civil Engineers, vol. 106, no. 2, pp. 81-92, 1980.

[42] C. S. Draper, J. P. Walker, P. J. Steinle, R. A. M. de Jeu, and T. R. H. Holmes, "An evaluation of AMSR-E derived soil moisture over Australia," Remote Sensing of Environment, vol. 113, no. 4, pp. 703-710, 2009.

[43] E. Cho, M. Choi, and W. Wagner, "An assessment of remotely sensed surface and root zone soil moisture through active and passive sensors in northeast Asia," Remote Sensing of Environment, vol. 160, pp. 166-179, 2015.

[44] C. Rüdiger, J.-C. Calvet, C. Gruhier, T. R. H. Holmes, R. A. M. de Jeu, and W. Wagner, "An intercomparison of ERS-Scat and AMSR-E soil moisture observations with model simulations over France," Journal of Hydrometeorology, vol. 10, no. 2, pp. 431447, 2009.

[45] I. R. Calder, R. J. Harding, and P. T. W. Rosier, "An objective assessment of soil-moisture deficit models," Journal of Hydrology, vol. 60, no. 1-4, pp. 329-355, 1983.

[46] K. R. Rushton, V. H. M. Eilers, and R. C. Carter, "Improved soil moisture balance methodology for recharge estimation," Journal of Hydrology, vol. 318, no. 1, pp. 379-399, 2006.

[47] M. H. Khan, "Xinanjiang model on bird creek catchment in USA," Pakistan Journal of Agricultural Research, vol. 14, no. 4, pp. 373-382, 1993.

[48] Z. Ren-Jun, “The Xinanjiang model applied in China," Journal of Hydrology, vol. 135, no. 1, pp. 371-381, 1992.

[49] Q. J. Wang, "The genetic algorithm and its application to calibrating conceptual rainfall-runoff models," Water Resources Research, vol. 27, no. 9, pp. 2467-2471, 1991.

[50] R.-J. Zhao, “The Xinanjiang model applied in China," Journal of Hydrology, vol. 135, no. 1-4, pp. 371-381, 1992.

[51] R.-J. Zhao, X. R. Liu, and V. P. Singh, “The Xinanjiang model," in Computer Models of Watershed Hydrology, pp. 215-232, 1995.

[52] X.-M. Song, F.-Z. Kong, C.-S. Zhan, and J.-W. Han, "Hybrid optimization rainfall-runoff simulation based on Xinanjiang model and artificial neural network," Journal of Hydrologic Engineering, vol. 17, no. 9, pp. 1033-1041, 2012.

[53] C. Yao, Z. Li, Z. Yu, and K. Zhang, "A priori parameter estimates for a distributed, grid-based Xinanjiang model using geographically based information," Journal of Hydrology, vol. 468-469, pp. 47-62, 2012.

[54] L. Zhuo and D. Han, "Misrepresentation and amendment of soil moisture in conceptual hydrological modelling," Journal of Hydrology, vol. 535, pp. 637-651, 2016.

[55] R.-J. Zhao, “The Xinanjiang model," in Hydrological Forecasting Proceedings Oxford Symposium, vol. 129, pp. 351-356, IASH, 1980. 
[56] J. E. Nash and J. V. Sutcliffe, "River flow forecasting through conceptual models part I-a discussion of principles," Journal of Hydrology, vol. 10, no. 3, pp. 282-290, 1970.

[57] G. W. Snedecor and W. G. Cochran, Statistical Methods, Iowa State University Press, Ames, Iowa, USA, 7th edition, 1980.

[58] X. Chen, T. Yang, X. Wang, C.-Y. Xu, and Z. Yu, "Uncertainty intercomparison of different hydrological models in simulating extreme flows," Water Resources Management, vol. 27, no. 5, pp. 1393-1409, 2013.

[59] L. Zhuo, D. Han, Q. Dai, T. Islam, and P. K. Srivastava, "Appraisal of NLDAS-2 multi-model simulated soil moistures for hydrological modelling," Water Resources Management, vol. 29, no. 10, pp. 3503-3517, 2015.

[60] D. J. Leroux, Y. H. Kerr, E. F. Wood, A. K. Sahoo, R. Bindlish, and T. J. Jackson, "An approach to constructing a homogeneous time series of soil moisture using SMOS," IEEE Transactions on Geoscience and Remote Sensing, vol. 52, no. 1, pp. 393-405, 2014.

[61] R. Panciera, J. P. Walker, J. D. Kalma, E. J. Kim, K. Saleh, and J.-P. Wigneron, "Evaluation of the SMOS L-MEB passive microwave soil moisture retrieval algorithm," Remote Sensing of Environment, vol. 113, no. 2, pp. 435-444, 2009.

[62] W. Wagner, L. Brocca, V. Naeimi et al., "Clarifications on the "Comparison between SMOS, VUA, ASCAT, and ECMWF soil moisture products over four watersheds in US"," IEEE Transactions on Geoscience and Remote Sensing, vol. 52, no. 3, pp. 1901-1906, 2014.

[63] Y. Chen, K. Yang, J. Qin, L. Zhao, W. Tang, and M. Han, "Evaluation of AMSR-E retrievals and GLDAS simulations against observations of a soil moisture network on the central Tibetan Plateau," Journal of Geophysical Research Atmospheres, vol. 118, no. 10, pp. 4466-4475, 2013.

[64] Y. H. Kerr, "Soil moisture from space: where are we?" Hydrogeology Journal, vol. 15, no. 1, pp. 117-120, 2007.

[65] T. Schmugge, Soil Moisture Sensing with Microwave Radiometers, LARS Symposia, 1980.

[66] X. Wang, H. Xie, H. Guan, and X. Zhou, "Different responses of MODIS-derived NDVI to root-zone soil moisture in semi-arid and humid regions," Journal of Hydrology, vol. 340, no. 1-2, pp. 12-24, 2007.

[67] G. Wahba and J. Wendelberger, "Some new mathematical methods for variational objective analysis using splines and cross validation," Monthly Weather Review, vol. 108, no. 8, pp. 1122-1143, 1980.

[68] S. Louvet, T. Pellarin, A. Al Bitar et al., "SMOS soil moisture product evaluation over West-Africa from local to regional scale," Remote Sensing of Environment, vol. 156, pp. 383-394, 2015.

[69] R. Rahmoune, P. Ferrazzoli, Y. H. Kerr, and P. Richaume, "SMOS level 2 retrieval algorithm over forests: description and generation of global maps," IEEE Journal of Selected Topics in Applied Earth Observations and Remote Sensing, vol. 6, no. 3, pp. 1430-1439, 2013.

[70] M. Pan, A. K. Sahoo, E. F. Wood, A. Al Bitar, D. Leroux, and Y. H. Kerr, "An initial assessment of SMOS derived soil moisture over the continental United States," IEEE Journal of Selected Topics in Applied Earth Observations and Remote Sensing, vol. 5, no. 5, pp. 1448-1457, 2012.

[71] M. Piles, A. Camps, M. Vall-Llossera et al., "Downscaling SMOS-derived soil moisture using MODIS visible/infrared data," IEEE Transactions on Geoscience and Remote Sensing, vol. 49, no. 9, pp. 3156-3166, 2011.
[72] D. Han and W. Z. W. Jaafar, "Model structure exploration for index flood regionalization," Hydrological Processes, vol. 27, no. 20, pp. 2903-2917, 2013.

[73] W. Z. W. Jaafar, J. Liu, and D. Han, "Input variable selection for median flood regionalization," Water Resources Research, vol. 47, no. 7, Article ID W07503, 2011. 

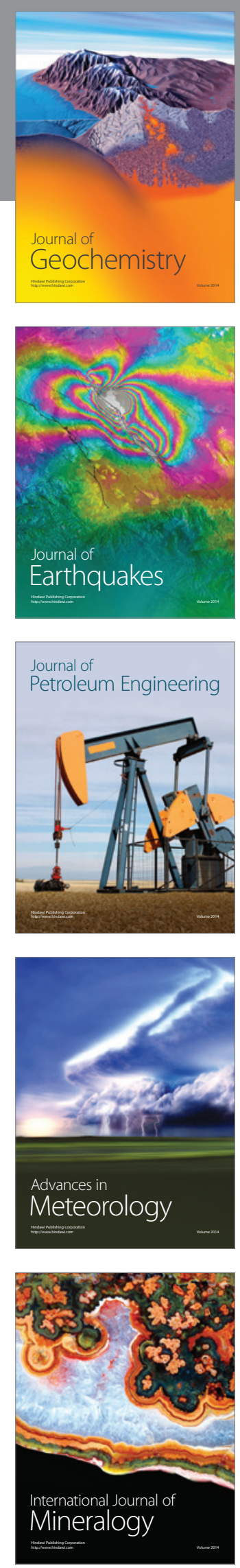
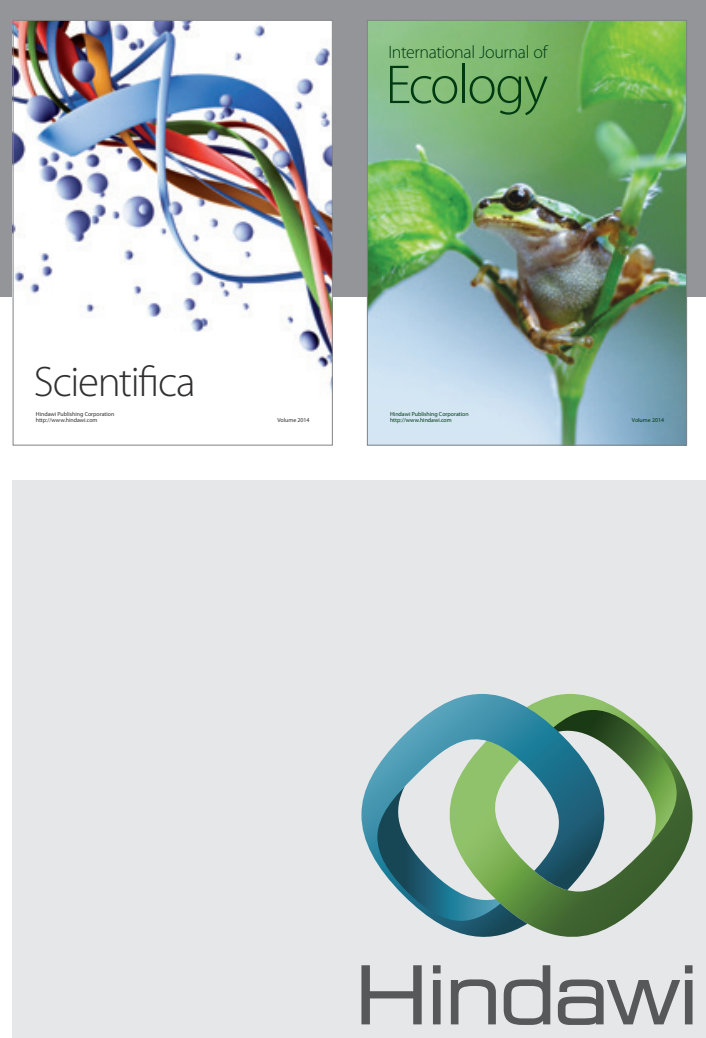

Submit your manuscripts at

https://www.hindawi.com
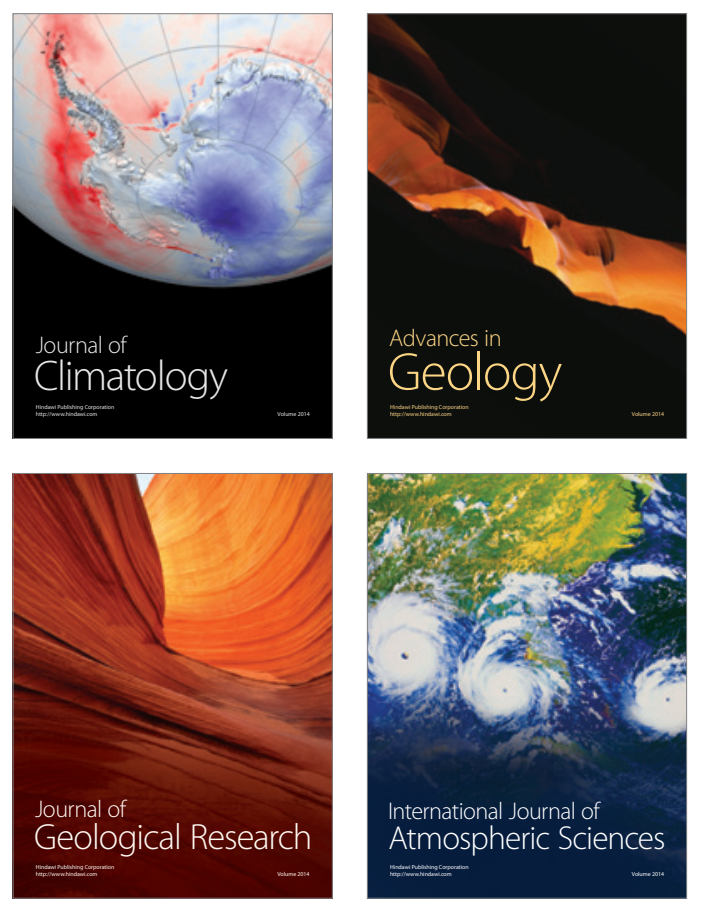

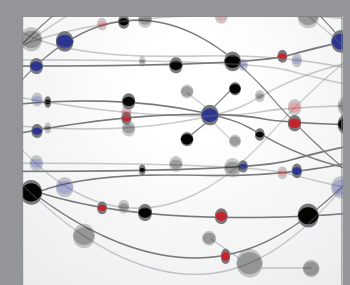

The Scientific

\section{World Journal}
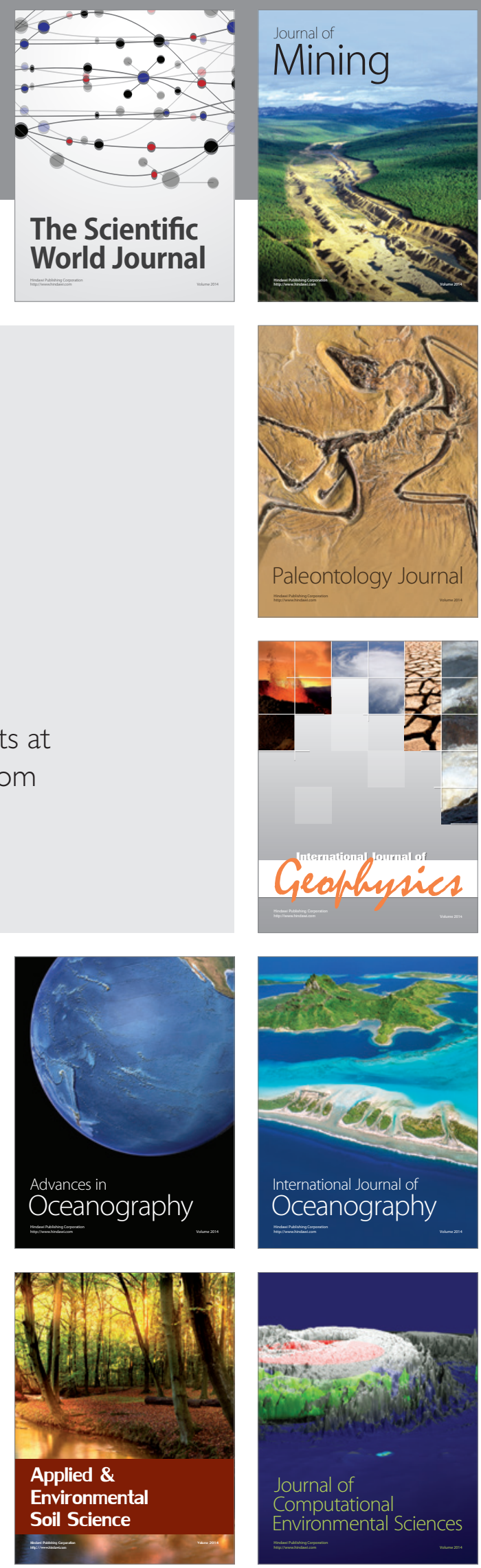